\title{
Oficinas regionais, influências de muitas e desvairadas partes: o caso dos suportes de madeira das pinturas maneiristas de Belchior de Matos da ermida de Geraldes (Peniche, Portugal)
}

\author{
António João Cruz, Elisabete Ferreira, Alexandra Lauw, Carla Rego, Helena Pereira
}

\begin{abstract}
Resumo: As duas pinturas, representando Santa Luzia e o Martírio de São Sebastião, feitas por Belchior de Matos (c. 1570-1628) para uma pequena ermida de Peniche, no início do século XVII, têm suportes de madeira que as primeiras observações, realizadas no âmbito de uma intervenção de conservação e restauro, sugeriram ter excelente qualidade e influências de construção que contrastam com o que seria expectável numa encomenda menor de um modesto e mal pago artista de província. Por isso, com o objectivo de aprofundar o caso e contribuir para o conhecimento das pequenas oficinas regionais de pintura do período maneirista, foi feito um estudo pormenorizado desses suportes, incluindo a moldura e a camada de preparação, com recurso a métodos laboratoriais (observação com lupa binocular, fotografia, dendrocronologia, microscopia óptica e FTIR). Concluiu-se, efectivamente, que os painéis mostram que as oficinas regionais de pintura, ao contrário do que se poderia prever, não funcionavam necessariamente isoladas e fechadas sobre si próprias e podiam ter um diversificado conhecimento técnico que, além de soluções originais, envolvia práticas com diferentes origens geográficas, do norte ao sul da Europa, que, com mais estudos de casos, importa esclarecer até que ponto estavam ou não consolidadas em Portugal.
\end{abstract}

Palavras-chave: pintura, suporte de madeira, carvalho do Báltico, tradições técnicas, influências técnicas

\section{Talleres provinciales, influencias de muchas y variadas partes del mundo: el caso de los soportes de madera de las pinturas manieristas de Belchior de Matos de la iglesia de Geraldes (Peniche, Portugal)}

Resumen: Las dos pinturas, que representan a Santa Luzia y el Martirio de São Sebastião, realizadas por Belchior de Matos (c. 15701628) para una pequeña ermita en Peniche, a principios del siglo XVII, tienen soportes de madera que las primeras observaciones, llevado a cabo como parte de una intervención de conservación y restauración, sugirieron tener una excelente calidad e influencias de construcción que contrastan con lo que se esperaría en un orden menor de un artista provincial modesto y mal pagado. Por lo tanto, con el objetivo de profundizar el caso y contribuir para lo conocimiento de los pequeños talleres regionales de pintura del período manierista, se realizó un estudio detallado de estos soportes, incluido el marco y la capa de preparación, utilizando métodos de laboratorio (observación con lupa binocular, fotografía, dendrocronología, microscopía óptica y FTIR). Se concluyó que los paneles muestran que los talleres regionales de pintura, al contrario de lo que se podría predecir, no necesariamente operaban aislados y cerrados y podían tener un conocimiento técnico diversificado que, además de las soluciones originales, envolvía prácticas con diferentes orígenes geográficos, de norte a sur de la Europa, que, con más estudios de caso, es importante aclarar en qué medida se consolidaron o no en Portugal.

Palabras clave: pintura, soporte de madera, roble báltico, tradiciones técnicas, influencias técnicas

Provincial workshops, influences from many and varied parts of the world: the case of the wooden supports of Belchior de Matos' Mannerist paintings of Geraldes' church (Peniche, Portugal)

Abstract: The present paper focuses on the study of two paintings, representing Saint Lucy and the Martyrdom of Saint Sebastian, made by Belchior de Matos (c. 1570-1628), for a small church in Peniche, in the early 17th century. The first observations made in 
the context of a conservation-restoration intervention showed that the wooden supports had an excellent quality and construction influences that contrast with what would be expected in a small commission to a modest and underpaid provincial artist. Thus, a detailed study of these supports, including the frame and the ground layer, was made using analytical techniques (observation with binocular loupe, photography, dendrochronology, optical microscopy and FTIR) in order to develop further the practices of small provincial painting workshops of the Mannerist period. In fact, contrary to what might be expected, the panels show that these workshops did not necessarily work in isolation but that they possessed a diversified technical knowledge that, besides original solutions, included practices from different geographical origins, from northern to southern Europe. With more case studies, it is important to clarify the extent to which they were or were not consolidated in Portugal.

Keywords: painting, wood support, Baltic oak, technical traditions, technical influences

\section{Introdução}

Do antigo retábulo-mor da ermida de São Sebastião e Santa Luzia, do lugar de Geraldes, freguesia de Atouguia da Baleia, concelho de Peniche, são conhecidas duas pequenas pinturas sobre madeira que formavam um díptico: uma representa Santa Luzia [figura 1] e a outra o Martírio de São Sebastião [figura 2]. Até agora arrecadadas na igreja matriz de Geraldes, segundo o historiador Vítor Serrão, são da autoria do pintor maneirista Belchior de Matos (c. 1570-1628) e foram executadas na década de 1610-1620 (Serrão 1981: 36).
Sobre o pintor, a primeira referência documental conhecida data de 1591 (Serrão 1981: 21-22). Nesta ocasião, ainda jovem, estava no Porto e era "criado" e "oficial pintor" na oficina do mestre lisboeta Diogo Teixeira, um dos mais elogiados pintores da época, com estatuto aristocrático e extensa obra realizada por todo o país, que então trabalhava no retábulo-mor da igreja da Misericórdia. Belchior de Matos, como aprendiz, tinha como função preparar as tintas, engessar e aparelhar as tábuas, preparando-as para a pintura, e, no final, ajudar na colocação dos painéis no retábulo. Nos anos seguintes continuou a trabalhar com Diogo Teixeira, ainda que tenha
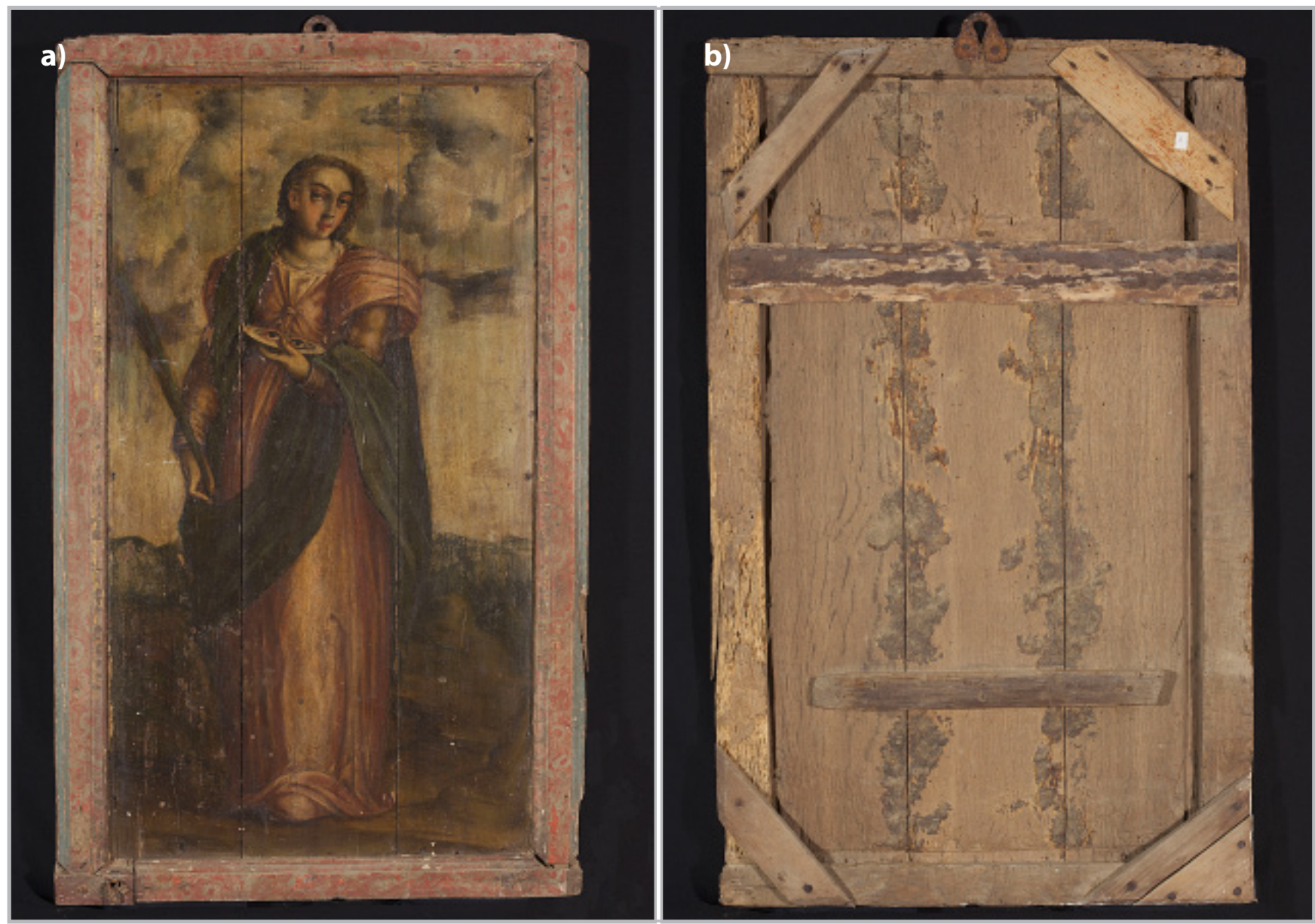

Figura 1.- Pintura representando Santa Luzia: frente (a) e verso (b). A travessa inferior é a única que persiste das travessas originais. 

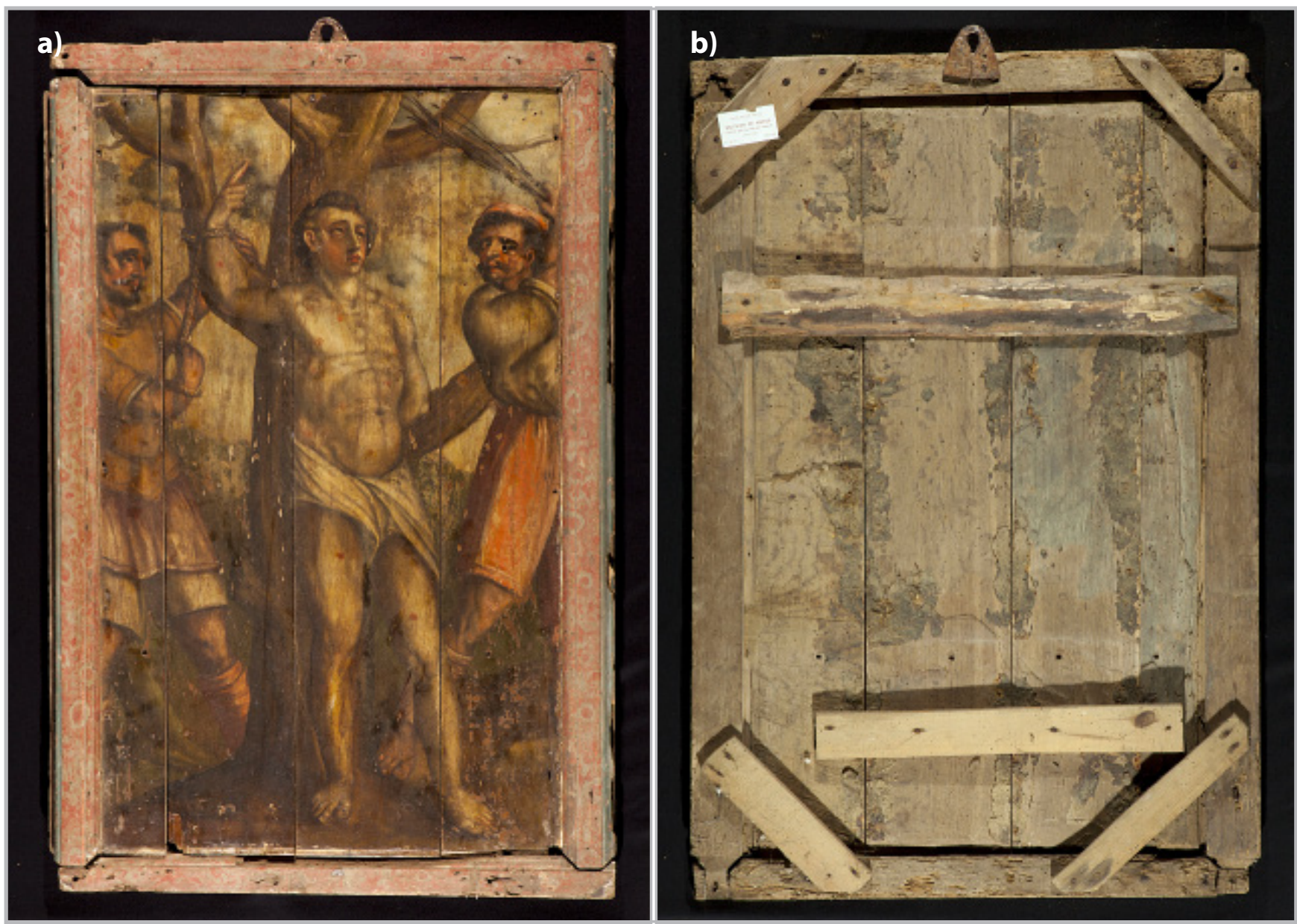

Figura 2.- Pintura representando o Martírio de São Sebastião: frente (a) e verso (b).

adquirido o estatuto de pintor autónomo, e os dois, em 1595, realizaram o retábulo-mor da ermida do Espírito Santo, das Caldas da Rainha. Após conclusão desta obra, Belchior de Matos fixou-se nesta cidade, onde residiu até à morte, em 1628 (Serrão 1981: 21-22).

Belchior de Matos foi "um pintor de província" (Serrão 1989) e, a partir do estabelecimento da sua oficina nas Caldas da Rainha, satisfez várias empreitadas pouco relevantes, maioritariamente destinadas a retábulos-mor de pequenas ermidas ou a capelas laterais de igrejas pertencentes a localidades próximas da cidade. Trabalhou também como pintor de varas e andores, de tábuas avulsas, como dourador de colunas e de frontispícios, como "renovador" de painéis antigos e engessador de tábuas. Esta actividade de engessador, muito relevante para o tema do presente estudo, está documentada através de registos de pagamentos efectuados em 1596, 1599, 1621, 1622, 1623, 1624 e 1626 (Serrão 1981: 60-61, 68-71).

Embora tenha sido incluído na lista dos privilegiados do Hospital de Nossa Senhora do Pópulo, das Caldas da Rainha, Belchior de Matos foi sempre visto, sobretudo, como um operário e artífice habilidoso, que também era pintor a óleo, sendo os seus trabalhos pagos invariavelmente segundo uma tabela muito abaixo do que era cobrado por outros pintores (Serrão 1981). Do ponto de vista artístico, as suas pinturas têm cores ácidas, mostram figuras robustas, distorcidas, alongadas e com músculos bem definidos, e evidenciam teatralidade de gestos e de atitudes - como é característico da pintura maneirista (Serrão 1981: 28; Silva 1996: 22). Porém, do ponto de vista técnico, denotam alguma dificuldade na representação das figuras (Serrão 1981: 32), especialmente visível no desenho de pés e de mãos.

As duas obras da ermida de Geraldes apresentam essas características gerais da pintura de Belchior de Matos, tendo sido descritas como uma "encomenda menor" (Serrão 1981: 36), "certamente mal paga e, por isso mesmo, de acabamento deficiente" (Serrão 1981: 78), que "revela graves deficiências de desenho e um tratamento seco da matéria cromática" (Serrão 1981: 36). No entanto, durante o estudo efectuado no âmbito da intervenção de conservação e restauro a que as pinturas foram sujeitas no Instituto Politécnico de Tomar, em 2018-2019, foram notadas diversas particularidades do suporte que não seriam expectáveis numa obra menor de um pintor regional. Mais concretamente, as observações efectuadas sugeriram o uso de materiais e procedimentos com origens ou influências geograficamente diversas, muito 
para além do espaço regional em que se desenvolveu a actividade do pintor e das limitadas ambições das obras. Essa aparente contradição é reforçada pelo anacronismo artístico e fechamento às novidades (Serrão 1989: 172) que se manifesta de forma notória na obra daquele que era conhecido como o pintor das Caldas e foi descrito como "um artista sem inovação, conservador e modesto" (Serrão 1981: 48). Além disso, as observações sugeriram também o uso nos suportes de materiais de grande qualidade e a adopção de bons procedimentos técnicos para a sua construção, algo que não se esperaria encontrar numa oficina como a de Belchior de Matos. Considerou-se então que o estudo mais detalhado dos dois suportes e o seu enquadramento nas práticas da época poderia ser uma significativa contribuição para o conhecimento das oficinas regionais de pintura, que pouco ou nada têm interessado os estudos laboratoriais mas que são tão importantes para a História da Arte como os artistas de maior craveira e reconhecimento, pelo quadro sociológico que igualmente ajudam a compor (Serrão 1989).

É esse estudo dos suportes das duas pinturas de Belchior de Matos, com o recurso a métodos de exame e análise, o tema do presente artigo. Além da caracterização dos mesmos, incluindo a moldura e a camada de preparação, pretende-se perceber até que ponto uma oficina com actividade apenas regional, artisticamente fechada às influências exteriores, afinal usava materiais e técnicas que vinham de fora.

Adicionalmente, de uma forma mais geral, pretende-se contribuir para o conhecimento dos suportes de pintura usados em Portugal que, como se ilustra aqui, podem ser muito informativos, mas aos quais pouca atenção é dada nos estudos publicados, sendo ainda escassa a informação detalhada disponível.

\section{Metodologia}

Para a caracterização geral dos suportes, foi fundamental a informação obtida através do contacto com as obras durante a intervenção de conservação e restauro. Para isso, além da observação directa, foi usada uma lupa binocular com ampliação até 40× (Leica M320 IVC) e um microscópio digital de mão, com fibra óptica, com ampliação até 225× (Dino-lite AM7013MZT e filtro polarizador). O facto de as juntas dos painéis estarem abertas e de estes terem sido desmontados durante a intervenção facilitou determinadas observações. Foi efectuada fotografia geral das obras com iluminação normal e com luz rasante com uma máquina fotográfica Canon EOS 5D Mark II e fotografia documental de pormenores com um smartphone Huawei ANE-LX1.

A datação dos suportes foi realizada através de uma abordagem dendrocronológica. A madeira foi previamente desbastada na secção transversal, com uma lâmina, de forma a se observarem nitidamente os anéis de crescimento. A datação foi realizada através de técnica baseada na obtenção de macrofotografias na secção transversal de cada tábua com recurso a uma máquina fotográfica digital (Canon EOS 1100D) (Lauw et al. 2013). A medição dos anéis de crescimento foi efectuada com recurso ao programa Image Analysis (Analysis 2.1), através da exibição sequencial das fotografias. A datação final obteve-se através do programa TSAP Win Scientific 4.64 (Rinntech), usando bases de dados de cronologias-padrão. A vantagem deste método é permitir a visualização dos anéis de crescimento para possíveis reavaliações futuras e evitar a repetição do manuseamento das pinturas.

Para o estudo estratigráfico e caracterização da preparação, foram retiradas microamostras da camada cromática que foram montadas em resina epóxida Epoxicure (Buehler), e observadas num microscópio óptico Olympus $\mathrm{CH} 30$ com máquina fotográfica acoplada Olympus DP10. Foram igualmente recolhidas amostras da preparação e do material aplicado no verso dos suportes. Estas foram analisadas por espectroscopia de infravermelho com transformada de Fourier (FTIR) num espectrómetro Alpha (Bruker), em modo ATR, entre 4000 e $400 \mathrm{~cm}^{-1}$, com resolução de $4 \mathrm{~cm}^{-1}$. As fibras constituintes do material do verso foram identificadas por microscopia óptica com recurso ao corante de Herzberg.

Embora não sejam aqui expressamente apresentados quaisquer resultados obtidos dessa forma, para o estudo material das pinturas utilizou-se igualmente fotografia de fluorescência de ultravioleta, fotografia de infravermelho, radiografia e equipamento não invasivo de espectrometria de fluorescência de raios $X$.

\section{Descrição geral dos suportes}

O suporte da pintura representando Santa Luzia tem 102 $\mathrm{cm}$ de altura e $56 \mathrm{~cm}$ de largura, sendo constituído por 3 tábuas dispostas na vertical [figura 1]. O do Martírio de São Sebastião tem a mesma altura mas mede $62 \mathrm{~cm}$ de largura e é composto por 4 tábuas, igualmente na vertical [figura 2]. A espessura, em média, é de $2,2 \mathrm{~cm}$ e de $1,5 \mathrm{~cm}$, respectivamente.

No verso, cada um dos suportes apresentava originalmente duas travessas horizontais, das quais apenas uma não foi substituída e persiste [figuras 1 e 2]. Quando as pinturas foram recebidas para tratamento, todas as juntas estavam completamente abertas, sendo as tábuas mantidas na sua posição por essas travessas e pelas molduras policromadas que aparentam ser originais, ainda que tenham sido repintadas.

A dimensão total das obras, com as molduras, é de $112 \mathrm{~cm}$ de altura por $69 \mathrm{~cm}$ de largura no caso da Santa Luzia e de $112 \mathrm{~cm}$ de altura por $74 \mathrm{~cm}$ de largura no caso do Martírio de São Sebastião (dimensões após a intervenção). 


\section{As tábuas}

A observação macroscópica, na secção transversal dos suportes, da estrutura celular da madeira sugere que esta é do género Quercus. Dada a impossibilidade de remoção de amostras para o estudo anatómico ao nível microscópico, não foi possível a identificação da espécie. Porém, considerando os resultados do estudo dendrocronológico sobre a proveniência da madeira, é expectável que se trate de Quercus robur ou Quercus petraea, duas espécies muito semelhantes do ponto de vista anatómico.

Através da comparação dos padrões de crescimento das sete tábuas analisadas, constatou-se que duas tábuas da pintura de Santa Luzia (I e III) [figura 3a] e uma tábua do Martírio de São Sebastião (II) [figura 3b] provêm da mesma árvore (ver datação por dendrocronologia).

As tábuas revelam cuidado na escolha, tal como era habitual no norte da Europa (Campbell, Foister 1997). Em primeiro lugar, são de corte radial ou radial puro (segundo a terminologia portuguesa de Helena Melo (Melo 2012: 212), baseada em Pascale Fraiture) [figura 3], minimizando assim a contracção da madeira e os respectivos problemas. Através da observação das secções transversais, não se observou a existência de anéis de borne. Superficialmente não se observou qualquer nó, ainda que exista um pequeno nó no interior de uma das tábuas [figura 4]. Finalmente, a qualidade da madeira resulta dos anéis relativamente finos, que têm reduzida tendência de deformação (Fraiture 2012): nas três tábuas provenientes da mesma árvore a espessura média é de 1,30-1,40 mm e nas restantes é significativamente inferior (ver abaixo).

Ainda que usada frequentemente na pintura portuguesa dos séculos $\mathrm{XV}$ e XVI, não seria expectável encontrar carvalho do Báltico em pinturas, como estas, de fraca qualidade e mal pagas, uma vez que era madeira de muito boa qualidade e dispendiosa, não apenas por causa da sua qualidade mas também devido ao seu transporte desde as longínquas florestas do norte da Europa. Além disso, a procura e os preços do carvalho do Báltico foram excepcionalmente elevados no início do século XVII (Wadum 1998: 151).
Belchior de Matos tinha várias alternativas. Por exemplo, em Espanha, o mais frequente era o uso de espécies autóctones, especialmente pinho e nogueira (Bruquetas Galán 2002: 199-201). Em Portugal, não obstante o predomínio do carvalho do Báltico, também eram usadas espécies locais, mesmo em encomendas de muito maior relevância: nalgumas oficinas a escolha recaía sobre o castanho, mas são igualmente conhecidas pinturas sobre madeira de nogueira, árvores de fruto e pinho (Esteves 2003; Klein 2012) e um tratado da primeira metade do século XVII menciona igualmente o cedro e o cipreste (Monteiro, Cruz 2010: 273).

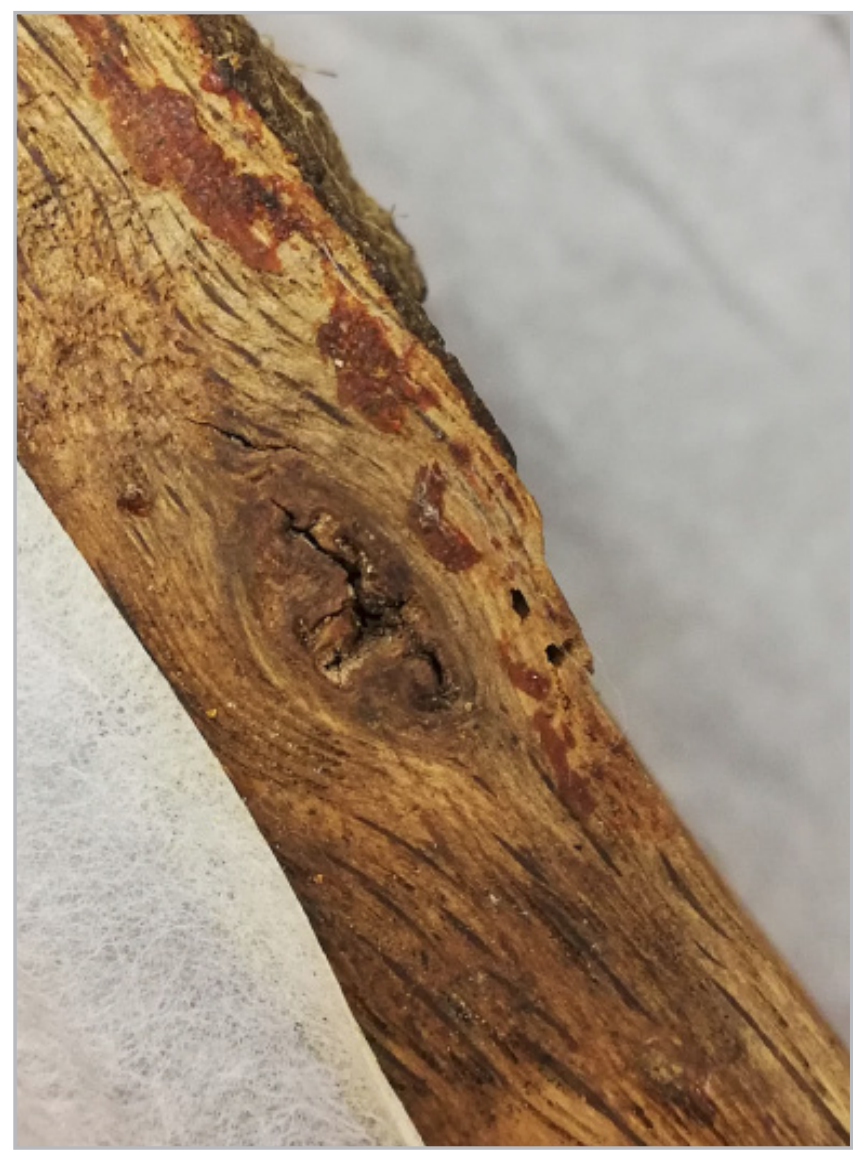

Figura 4.- Nó na secção lateral (lado da junta) de uma das tábuas do Martírio de São Sebastião

a)

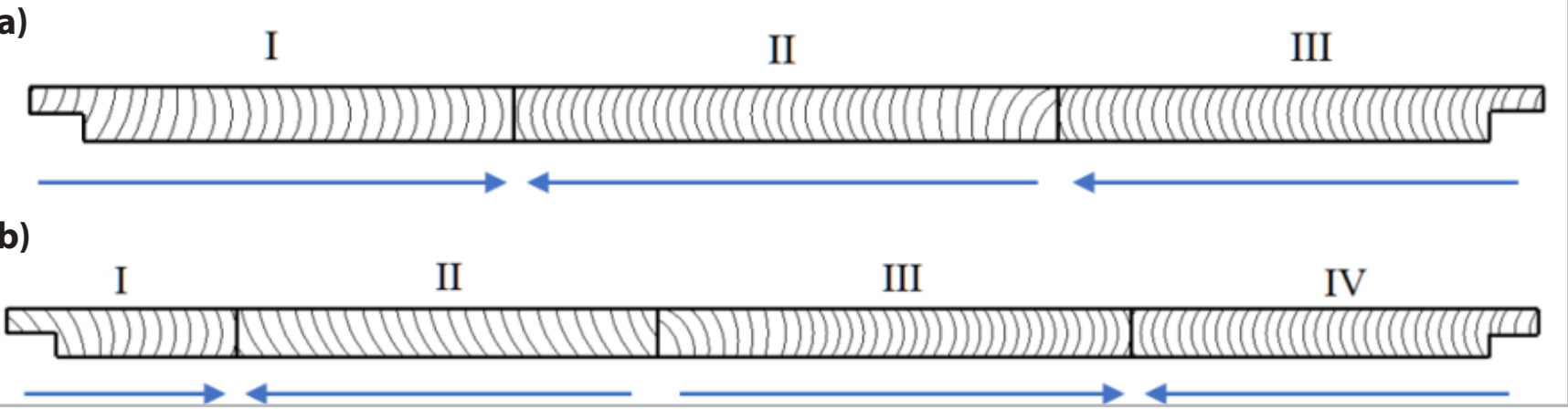

Figura 3.- Corte e disposição das tábuas (vistas a partir da base, com a face pintada virada para cima): a) Santa Luzia; b) Martírio de São Sebastião. As setas indicam o sentido do crescimento dos anéis (da medula para a casca). 
Todas as tábuas têm $102 \mathrm{~cm}$ de comprimento, correspondendo à altura dos painéis, e a sua largura está compreendida entre 9,3 e 20,2 cm [tabela 1]. A diferença de largura entre o topo e a base de cada tábua é na maior parte dos casos de $0,1 \mathrm{~cm}$ ou inferior, sendo, no máximo, de $0,4 \mathrm{~cm}$. A espessura varia entre 2,0 e 2,5 cm no painel de Santa Luzia e entre 1,0 e 2,0 cm no painel do Martírio de São Sebastião. As diferenças entre as duas obras manifestam-se também na regularidade do verso: as tábuas do painel de Santa Luzia têm superfície regular, devido a corte com serra, enquanto no painel do Martírio de São Sebastião as tábuas das extremidades têm muito menor espessura do que as centrais e, salvo no caso da tábua III, apresentam superfície muito irregular. Este facto, assim como a descontinuidade de marcas entre tábuas, permite concluir que o tratamento do verso dos suportes foi feito antes de as tábuas terem sido assembladas. A irregularidade do verso de algumas tábuas não é indiciadora de falta de cuidado pois corresponde a uma situação muito frequente em Espanha (Marijnissen 1985: 66), ainda que o caso seja diferente na Flandres, onde, conforme a dimensão e o destino das pinturas, o acabamento do verso podia ser muito cuidado ou inexistente (Campbell, Foister 1997; Marijnissen 1985: 65; Verougstraete 2015: 32-34). A respeito da mistura de tábuas com diferente acabamento do verso no painel

Tabela 1.- Corte e largura das tábuas.

\begin{tabular}{|l|c|c|c|c|}
\hline Pintura & Tábua & \multirow{2}{*}{ Corte } & \multicolumn{2}{|c|}{ Largura (cm) } \\
\cline { 4 - 5 } & & & Topo & Base \\
\hline \multirow{3}{*}{ Santa Luzia } & $\mathrm{I}$ & $\mathrm{RP}$ & 18,0 & 18,0 \\
\cline { 2 - 5 } & $\mathrm{II}$ & $\mathrm{R}$ & 20,0 & 20,2 \\
\cline { 2 - 5 } & $\mathrm{III}$ & $\mathrm{R}$ & 18,4 & 18,4 \\
\hline \multirow{3}{*}{$\begin{array}{l}\text { Martírio de São } \\
\text { Sebastião }\end{array}$} & $\mathrm{I}$ & $\mathrm{R}$ & 9,4 & 9,3 \\
\cline { 2 - 5 } & $\mathrm{II}$ & $\mathrm{R}$ & 17,0 & 17,0 \\
\cline { 2 - 5 } & $\mathrm{III}$ & $\mathrm{R}$ & 19,2 & 19,1 \\
\cline { 2 - 5 } & $\mathrm{IV}$ & $\mathrm{RP}$ & 16,0 & 16,4 \\
\hline
\end{tabular}

Corte: $\mathrm{R}=$ radial; $\mathrm{RP}=$ radial puro do Martírio de São Sebastião é interessante notar-se que o mesmo se observa numa pintura de Pedro Berruguete que também apresenta no verso duas travessas como as pinturas em estudo (Bruquetas Galán 2002: 214).

A espessura destas tábuas está de acordo como que era usual em Portugal, onde a espessura parecia ser superior ao que era comum no norte da Europa. A largura, no máximo de $20 \mathrm{~cm}$, fica consideravelmente aquém da largura máxima das tábuas de carvalho do Báltico usadas em pinturas feitas em Portugal, as quais, na maior parte dos casos, tinham, pelo menos, $25 \mathrm{~cm}$ (Melo 2012: 90-93). No entanto, a largura das tábuas de carvalho do Báltico diminuiu muito significativamente durante o primeiro terço do século XVII (Dubois, Fraiture 2011), pelo que, excluindo a tábua mais estreita, a largura deve estar de acordo com o que era habitual na época. Porém, ainda que fosse difícil usar apenas duas tábuas em cada suporte, uma vez que as tábuas de carvalho do Báltico raramente tinham mais do que $30 \mathrm{~cm}$ de largura (Verougstraete 2015: 15) e as pinturas têm $60 \mathrm{~cm}$ ou mais, no caso do Martírio de São Sebastião teria sido fácil usar apenas três tábuas, tal como acontece no painel de Santa Luzia, em vez das quatro.

Resumindo, as tábuas são de excelente qualidade, o que explica o bom estado em que se encontram, sem deformações significativas e sem fissuras.

\section{Datação por dendrocronologia}

Os anéis de crescimento das sete tábuas foram medidos, sempre que possível, no topo e na base das mesmas [tabela 2]. Nalguns casos foi impossível a medição em toda a largura devido à descontinuidade dos anéis e, por isso, há uma diferença significativa do número de anéis medidos nas duas extremidades de uma tábua. Das setes tábuas, duas resultam de crescimento que pode ser descrito como "muito lento", dada a espessura média dos anéis ser inferior a $1 \mathrm{~mm}$; duas de crescimento "lento", com uma espessura média dos anéis inferior a 1,2 $\mathrm{mm}$; e as restantes três de crescimento "médio", inferior a $2 \mathrm{~mm}$.

Tabela 2.- Avaliação dos anéis de crescimento.

\begin{tabular}{|c|c|c|c|c|c|c|}
\hline Pintura & Tábua & $\begin{array}{c}\text { N.o de anéis } \\
\text { medidos (topo/ } \\
\text { base) }\end{array}$ & $\begin{array}{l}\text { Espessura mínima } \\
\text { (mm) }\end{array}$ & $\begin{array}{c}\text { Espessura } \\
\text { máxima (mm) }\end{array}$ & $\begin{array}{c}\text { Espessura } \\
\text { média } \pm \text { desvio- } \\
\text { padrão }(\mathrm{mm})\end{array}$ & $\begin{array}{c}\text { N. }{ }^{\circ} \text { total de } \\
\text { anéis }\end{array}$ \\
\hline \multirow{3}{*}{ Santa Luzia } & 1 & $104 / 64$ & 0,58 & 2,28 & $1,36 \pm 0,41$ & 105 \\
\hline & II & $-/ 187$ & 0,33 & 2,07 & $0,97 \pm 0,37$ & 187 \\
\hline & III & $107 / 115$ & 0,60 & 2,51 & $1,37 \pm 0,42$ & 126 \\
\hline \multirow{4}{*}{$\begin{array}{l}\text { Martírio de São } \\
\text { Sebastião }\end{array}$} & 1 & $79 / 49$ & 0,36 & 1,81 & $0,99 \pm 0,42$ & 79 \\
\hline & ॥ & $97 /-$ & 0,50 & 2,82 & $1,30 \pm 0,43$ & 97 \\
\hline & III & $170 / 151$ & 0,45 & 2,30 & $1,02 \pm 0,34$ & 170 \\
\hline & IV & $122 /-$ & 0,71 & 2,21 & $1,13 \pm 0,23$ & 122 \\
\hline
\end{tabular}


A tabela 3 apresenta os coeficientes de correlação entre todos os padrões de crescimento das tábuas, constatandose que as tábuas I e III do painel de Santa Luzia e a tábua Il do painel do Martírio de São Sebastião foram obtidas de uma mesma árvore (tVH a variar de 19,5 a 20,7; valores assinalados a negrito). Os três padrões da mesma árvore foram sincronizados e combinados numa única série cronológica (I-III-II) de 126 anos. As baixas correlações das tábuas I e IV do painel do Martírio de São Sebastião relativamente às restantes tábuas analisadas (tVH a variar de 2,9 a 4,0) levantam a hipótese de não serem provenientes do mesmo local.

Para três das cinco séries cronológicas resultantes das duas pinturas em estudo foram obtidas correspondências estatisticamente significativas com cronologias-padrão de referência [Tabela 4] que permitem concluir que as madeiras têm como proveniência a região do Báltico. A datação do anel mais recente do painel de Santa Luzia corresponde ao ano de 1594 e do painel do Martírio de São Sebastião ao ano de 1599. Para as duas séries cronológicas das tábuas I e IV do painel do Martírio de São Sebastião não se encontrou correspondência nas cronologias-padrão usadas e, por isso, não foi possível obter uma data para as mesmas.

Para a datação das pinturas é necessário ter em consideração a remoção da zona de borne e o período de secagem das madeiras. Este era, no mínimo, de 2 anos e o borne, considerando a proveniência do carvalho, correspondia, no mínimo, a 9 anéis de crescimento (Klein 2010). Assim, as pinturas não foram executadas antes de 1610 (1599+9+2). Considerando-se o valor médio de 15 anéis na zona de borne, pode-se afirmar queé mais provável

Tabela 3.- Correlações (GIK GLS / tVH) entre as medidas dos anéis de crescimento das sete tábuas.

\begin{tabular}{|c|c|c|c|c|c|c|c|c|}
\hline \multirow{2}{*}{\multicolumn{2}{|c|}{ Tábuas }} & \multicolumn{3}{|c|}{ Santa Luzia } & \multicolumn{4}{|c|}{ Martírio de São Sebastião } \\
\hline & & I & II & III & 1 & II & III & IV \\
\hline \multirow{3}{*}{ Santa Luzia } & I & & & & & & & \\
\hline & $\|$ & $72^{* * *} / 7,2$ & & & & & & \\
\hline & III & $87 * * * / 19,5$ & $64^{* * *} / 6,1$ & & & & & \\
\hline \multirow{4}{*}{$\begin{array}{l}\text { Martírio de São } \\
\text { Sebastião }\end{array}$} & I & $60^{* * *} / 3,5$ & $62^{* * *} / 3,1$ & $36^{* * *} / 3,1$ & & & & \\
\hline & $\|$ & $87 * * * / 19,6$ & $71^{* * *} / 7,6$ & $97 * * * 20,7$ & $58^{* *} / 2,7$ & & & \\
\hline & III & $71^{* * *} / 6,9$ & $61^{* * *} / 4,4$ & $63^{* * *} / 6,5$ & $58^{* * *} / 3,1$ & $66^{* * *} / 5,9$ & & \\
\hline & IV & $67^{* * *} / 3,0$ & $68^{* * *} / 3,8$ & $64 * * * / 4,0$ & $64 * * / 3,5$ & $61 * * * / 3,5$ & $41 * * / 29$ & \\
\hline
\end{tabular}

Parâmetros estatísticos: GIK = Gleichläufigkeit (Grau de sincronização de duas sequências); GSL= Gleichläufigkeitswert (Grau de significância da sincronização de duas sequências: 99,9\% [***] e 99 \% [**]) (Eckstein, Bauch 1969); tVH - $t$-value Hollstein-standardization (Hollstein 1980).

Tabela 4.- Datação das pinturas.

\begin{tabular}{|c|c|c|c|c|c|}
\hline \multirow{2}{*}{ Pintura ou série } & \multirow{2}{*}{ Tábua } & \multirow{2}{*}{$\begin{array}{c}\text { Intervalo da série } \\
\text { cronológica (Data do } 1 .^{\circ} \text { anel } \\
\text { - Data do último anel) }\end{array}$} & \multicolumn{2}{|c|}{$\begin{array}{l}\text { Parâmetros } \\
\text { estatísticos }\end{array}$} & \multirow{2}{*}{ Cronologias de referência } \\
\hline & & & GIK, GSL & tVH & \\
\hline \multirow{3}{*}{ Santa Luzia } & 1 & \multicolumn{4}{|c|}{ Integrada na série I-III-II } \\
\hline & $\|$ & $1407-1593$ & $67^{* * *}$ & 7,0 & $\begin{array}{c}\text { Baltic 1; CHRONOMASFFL; NSG; } \\
\text { NGG }\end{array}$ \\
\hline & III & \multicolumn{4}{|c|}{ Integrada na série I-III-II } \\
\hline \multirow{4}{*}{ Martírio de São Sebastião } & I & \multicolumn{4}{|c|}{ Não datada } \\
\hline & II & \multicolumn{4}{|c|}{ Integrada na série I-III-II } \\
\hline & III & 1430-1599 & $68^{* * *}$ & 6,7 & CHRONOMASFFL; NSG \\
\hline & IV & \multicolumn{4}{|c|}{ Não datada } \\
\hline \multicolumn{2}{|c|}{ Série I-III-II } & 1469-1594 & $73^{* * *}$ & 8,0 & NSG; EG \\
\hline
\end{tabular}

Parâmetros estatísticos: ver Tabela 3.

Cronologias de referência: Baltic 1 (Hillam, Tyers 1995); EG = England Gemaeld MC 18 Fletcher, NGG = Niederlande Gesamt Gemaelde, NSG = Niederlande Sued Gemaelde (Peter Klein, não publicadas); CHRONOMASFFL (Alexandra Lauw, não publicada). 
que as pinturas sejam posteriores a $1616(1599+15+2)$. Ressalva-se, porém, que estas datas não têm em conta a eventual falta de anéis do cerne nem a possibilidade de um maior tempo de secagem e armazenamento das tábuas. Com efeito, nos séculos XVI e XVII, o tempo de secagem da madeira utilizada pelos pintores flamengos geralmente era superior a 2 anos, podendo chegar a 8 anos (Klein 2010). De qualquer forma, as datas referidas são compatíveis com o intervalo de 1610 a 1620 proposto para a realização das pinturas com base em considerações histórico-artísticas (Serrão 1981: 36), ainda que não possa ser excluída a possibilidade de serem posteriores a 1620.

\section{Construção dos suportes}

\section{—Disposição das tábuas}

As sete tábuas dispõem-se na vertical, isto é, alinhadas com o lado mais comprido das pinturas, minimizando o número de tábuas, e na posição em que a pressão resultante do peso se distribui de forma semelhante por todas as tábuas em vez de se acentuar nas tábuas da base caso a disposição fosse horizontal (Dunkerton et al. 1999: 216).

Em ambas as pinturas, as extremidades laterais dos painéis correspondem às extremidades mais antigas das tábuas [figura 3], como era comum na pintura flamenga (Verougstraete 2015: 41; Wadum 1998). Dessa forma, o lado mais resistente era o que ficava exposto ao exterior. Além disso, no Martírio de São Sebastião, as quatro tábuas estão dispostas de uma forma regular: nas três juntas, o lado mais antigo com o lado mais antigo e o lado mais recente com o lado mais recente [figura 3]. O facto de isso não acontecer no painel de Santa Luzia significa que foi considerado que o mais importante era o lado que ficava para fora, já que, por as tábuas serem em número ímpar, não era possível conciliar os dois critérios. Contudo, nesta pintura há a simetria resultante de as duas tábuas exteriores serem da mesma árvore, um tipo de simetria encontrado em obras flamengas (Verougstraete 2015: 43).

Ainda que a disposição regular seguida no Martírio de São Sebastião fosse comum no norte da Europa (Wadum 1998: 154), provavelmente o mais frequente nas tábuas cortadas radialmente era as juntas, excepto a central, envolverem lados diferentes das tábuas, ficando as da esquerda e da direita, independentemente do seu número, simetricamente dispostas com o lado mais antigo para fora. Deste modo minimizavam-se as tensões (Verougstraete 2015: 41-43). No entanto, parece que em Portugal nem sempre se prestava atenção à disposição das tábuas ao longo das juntas (Melo 2012: 97).

Nas tábuas com corte radial, a face exterior, isto é, a mais afastada da medula, dispõe-se alternadamente para a frente e para o verso dos painéis [figura 3], tal como alguns recomendavam com o objectivo de minimizar a deformação dos painéis (Alba González-Fanjul 2015: 125). Este procedimento, porém, devia ter efeitos significativos sobretudo quando as tábuas tinham corte tangencial, pelo que neste caso, em que o afastamento relativamente a um corte radial puro é mínimo, a relevância deste dado está apenas na atitude sistemática que parece revelar.

Nas duas pinturas, as tábuas mais estreitas são as das extremidades. Isto está de acordo com a tradição italiana (Castelli 2009), mas contraria a prática flamenga de as colocar no centro dos painéis de forma a afastar as juntas das extremidades onde, devido à ligação à moldura, as tensões eram mais intensas (Verougstraete 2015: 43). Nalguns casos, o uso de uma tábua larga no centro do painel tinha como objectivo evitar a colocação de juntas na área mais importante da composição e assim minimizar o risco de aparecimento de fissuras no motivo central da pintura (Dunkerton et al. 1999: 216; Wadum 1998: 155), mas não no presente caso pois, como adiante se detalha, não foi evitada a aplicação de cavilhas que originaram marcas visíveis no rosto das figuras.

\section{— Assemblagem e reforço}

Em ambas as pinturas, a união entre as tábuas foi efectuada por junta viva ou junta plana, como era comum quer no norte quer no sul da Europa. Frequentemente, nomeadamente em Portugal (Cordeiro 2013b), eram inseridas cavilhas na secção das tábuas, não tanto para reforço da união, mas sobretudo para garantir o correto alinhamento das tábuas durante a colagem (Castelli 2009; Wadum 1998). Porém, nas obras em estudo não foi empregue qualquer cavilha, algo que não era frequente em Portugal, mas que foi usado numa - mas apenas numa - das pinturas que Diogo Teixeira pintou para a Misericórdia do Porto, onde Belchior de Matos colaborou como ajudante (Sousa, Cruz 2012). Nas pinturas de Peniche, além disso, não foi detectada qualquer acumulação de adesivo nas superfícies em contacto, não obstante as excelentes condições de observação resultantes da total desmontagem do suporte durante a intervenção de conservação e restauro. A hipótese de não ter sido usado um adesivo, sugerida por esse facto, é apoiada pela ausência, nas superfícies em contacto, dos golpes que por vezes eram feitos com o objectivo de melhorar a ligação do adesivo (Castelli 2009; Verougstraete 2015: 46). Juntas sem adesivo não são comuns, mas está publicado o caso de um retábulo castelhano, um século mais antigo, onde a união das tábuas foi feita sem adesivo ou qualquer elemento de madeira ou metal inserido entre as tábuas, tendo sido usadas duas travessas de madeira na horizontal, aplicadas no verso de cada pintura, fixas com pregos de ferro introduzidos pela frente (Hodge et al. 1998). Contudo, não se pode excluir a possibilidade de, efectivamente, ter sido usado um adesivo nas pinturas em estudo pois, segundo reconstituições históricas, a sua visibilidade numa junta pode ser muito reduzida (Melo 2019). 
De qualquer forma, nas pinturas em estudo foram usadas travessas semelhantes às daquele retábulo castelhano, salvo terem sido aplicadas pela frente cavilhas de madeira em vez de pregos [figura 5]. O uso de travessas, seja com esse número e disposição ou não, era comum em Espanha como sistema de reforço das juntas previamente coladas (Bruquetas Galán 2002: 212-220), assim como em Itália (Castelli 2009; Uzielli 1998), mas era raro no norte da Europa (Marijnissen 1985: 66). As cavilhas de madeira eram muito utilizadas em Espanha para fixação das travessas (Bruquetas Galán 2002: 216; Véliz 1998: 139), enquanto em Itália eram empregues quase exclusivamente pregos de ferro (Castelli 2009; Uzielli 1998). Em Portugal são conhecidos casos de fixação das travessas quer com cavilhas de madeira, quer com pregos (Cordeiro 2013b).

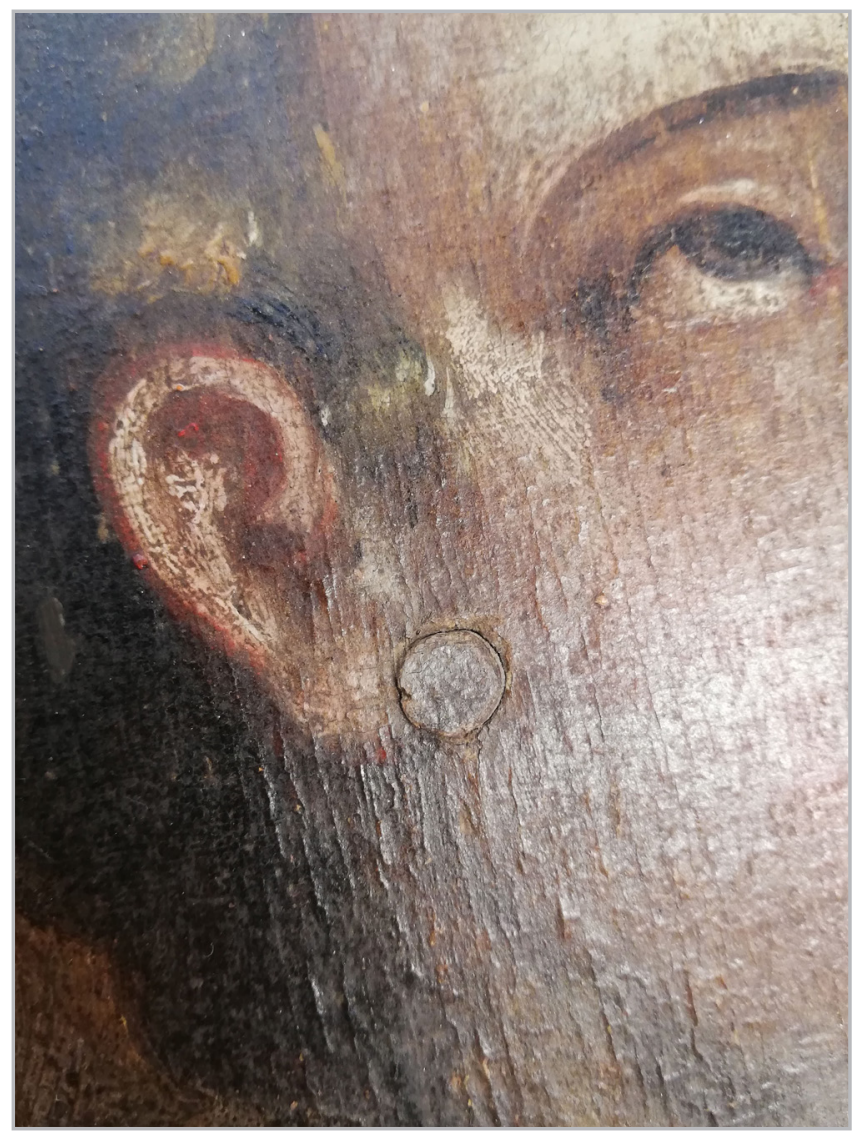

Figura 5.- Marca da cavilha no painel do Martírio de São Sebastião.

Nas duas obras, as travessas foram colocadas a cerca de 20-25 cm das extremidades, ficando afastadas $50-60 \mathrm{~cm}$ (tomando como referência a posição das cavilhas). Antes da sua colocação, o verso das tábuas do painel de Santa Luzia foi ajustado para melhor contacto das travessas; no outro caso não é evidente se isso sucedeu.

Tal como é perceptível na superfície da pintura [figura 5], cada travessa ligava-se a cada tábua por uma única cavilha, com cerca de $0,5 \mathrm{~cm}$ de diâmetro, geralmente colocada a meio da largura da tábua. Actualmente, das quatro travessas, apenas a travessa inferior do painel de Santa
Luzia é original e do total de 14 cavilhas apenas subsistem 11 , das quais só as três da travessa original estão inteiras, pois as outras partiram-se ou foram cortadas no verso. As travessas não originais estavam fixas com pregos.

No caso da travessa superior do Martírio de São Sebastião, a posição da cavilha na tábua III é muito excêntrica relativamente à tábua, tendo ficado, no entanto, a meio da largura do painel. Deste modo, a cavilha não ficou no rosto do santo, mas apenas junto à orelha [figura 5]. Como a cavilha da travessa inferior foi colocada no centro da tábua, pode pensar-se que aquele deslocamento da cavilha superior teve como objectivo evitar qualquer marca no rosto do santo. Porém, como semelhante cuidado não houve nem no caso do algoz à sua esquerda nem, o que é mais relevante, na outra pintura, no rosto de Santa Luzia, fica por esclarecer a situação.

No caso do painel de Santa Luzia, como claramente se percebe pela marca junto à travessa original (igual a outra existente na zona da travessa superior), as travessas foram cortadas com um serrote depois de aplicadas [figura 6]. Este corte pode ter sido feito mais tarde, por exemplo, numa ocasião em que as pinturas mudaram de lugar, mas, ainda que possa parecer pouco racional, as observações efectuadas não permitem excluir a possibilidade de o corte ter sido feito logo após a sua aplicação. De qualquer modo, esse corte das travessas foi efectuado depois do rebaixo das extremidades do painel (cf. abaixo).

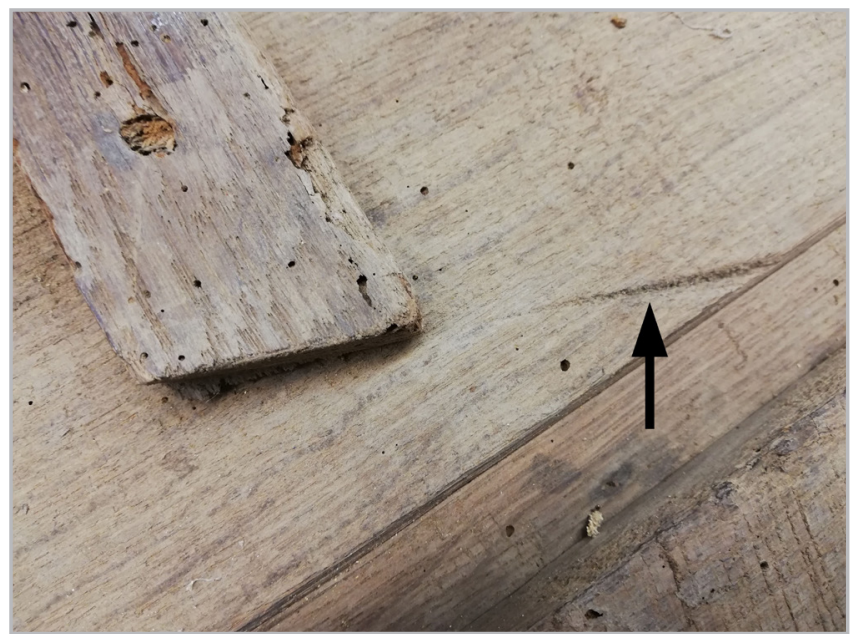

Figura 6.- Marca de serrote junta à travessa original do painel de Santa Luzia.

Depois de fixas as travessas, foi aplicada sobre as juntas [figuras 1 e 2] uma pasta de fibras [figura 7] e outro material que, actualmente, apresenta superfície irregular, grande rigidez e cor castanha escura. De acordo com os resultados de microscopia, as fibras são de linho ou cânhamo, mas, considerando o lúmen estreito, é mais provável serem de linho (Ilvessalo-Pfäffli 1995: 336-339). Segundo as análises por FTIR, o material que aglomera as fibras e as fixa ao suporte é colofónia [figura 8]. O espectro 
tem grande semelhança ao obtido para uma amostra de colofónia da Kremer Pigmente [tabela 5] (Prati et al. 2011), apresentando quer as bandas gerais das resinas diterpénicas (entre as quais a intensa banda $\mathrm{U}(\mathrm{C}=\mathrm{O})$ do grupo carbonilo a $1692 \mathrm{~cm}^{-1}$ e as bandas $\mathrm{U}(\mathrm{C}-\mathrm{H})$ dos grupos $\mathrm{CH}_{2}$ e $\mathrm{CH}_{3}$, respectivamente, a 2929 e $2869 \mathrm{~cm}^{-1}$ ), quer outras mais específicas (designadamente a banda a $702 \mathrm{~cm}^{-1}$ característica da colofónia e a banda a $1178 \mathrm{~cm}^{-1}$ relacionada com a fotodegradação das resinas) (Azémard et al. 2014; Derrick et al. 1999; Prati et al. 2011). As bandas que não constam do mencionado espectro de referência, surgem noutras amostras de colofónia (Azémard et al. 2014; Melo 2012: 243). Em particular, a banda a $2641 \mathrm{~cm}^{-1} \mathrm{faz}$ parte de um conjunto de bandas com reduzida intensidade características dessa resina (Azémard et al. 2014) devidas à dimerização do grupo carbonilo (Derrick et al. 1999: 104).

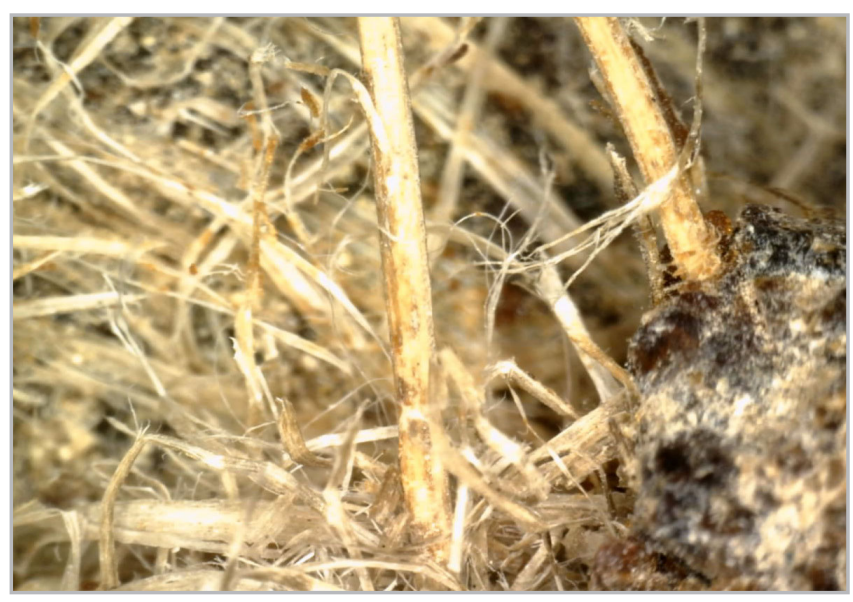

Figura 7.- Fibras no verso dos suportes (microscópio de mão, ampliação 250x).
Tabela 5.- Bandas do espectro de FTIR obtido para o material castanho aplicado no verso dos suportes e de amostra de referência de colofónia da Kremer Pigmente (Prati et al. 2011).

\begin{tabular}{|c|c|}
\hline \multicolumn{2}{|c|}{ N. ${ }^{\circ}$ de onda $\left(\mathrm{cm}^{-1}\right)$} \\
\hline Amostra das pinturas & Referência de colofónia \\
\hline \multicolumn{2}{|l|}{3394} \\
\hline 2929 & $2928(\mathrm{~m})$ \\
\hline 2869 & $2867(\mathrm{~m})$ \\
\hline \multicolumn{2}{|l|}{2641} \\
\hline 1692 & 1691 (s) \\
\hline \multicolumn{2}{|l|}{1609} \\
\hline 1455 & $1455(\mathrm{~m})$ \\
\hline 1384 & $1384(\mathrm{~m})$ \\
\hline 1237 & $1237(\mathrm{~m})$ \\
\hline 1178 & $1177(w)$ \\
\hline \multicolumn{2}{|l|}{1130} \\
\hline 1034 & $1035(w)$ \\
\hline 960 & $952(w)$ \\
\hline \multicolumn{2}{|l|}{908} \\
\hline 828 & $824(\mathrm{~m})$ \\
\hline 702 & $707(w)$ \\
\hline 651 & $658(s)$ \\
\hline 612 & $611(w)$ \\
\hline 561 & $561(\mathrm{~m}, \mathrm{sh})$ \\
\hline 534 & $540(s)$ \\
\hline \multirow[t]{2}{*}{466} & $478(w)$ \\
\hline & $449(w)$ \\
\hline 421 & $417(\mathrm{~m})$ \\
\hline
\end{tabular}

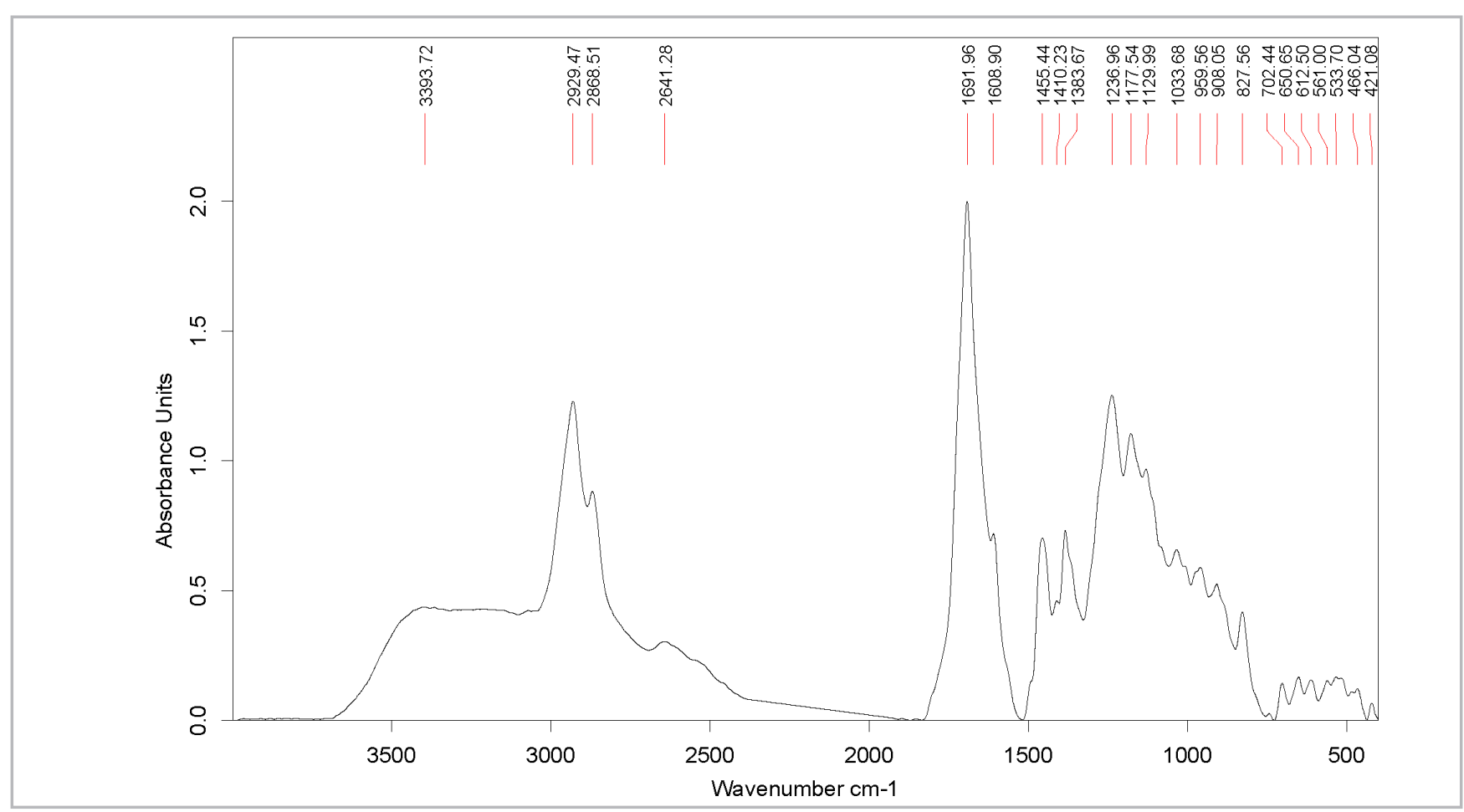

Figura 8.- Espectro de FTIR obtido para amostra de material misturado com as fibras no verso dos suportes. 
Esta pasta de fibras e colofónia foi aplicada após as travessas, pois interrompe-se nessa zona, e depois de o painel estar emoldurado, visto encontrar-se no rebaixo efectuado para encaixe na moldura (ver abaixo) e na própria moldura (na face interna) [figura 9].

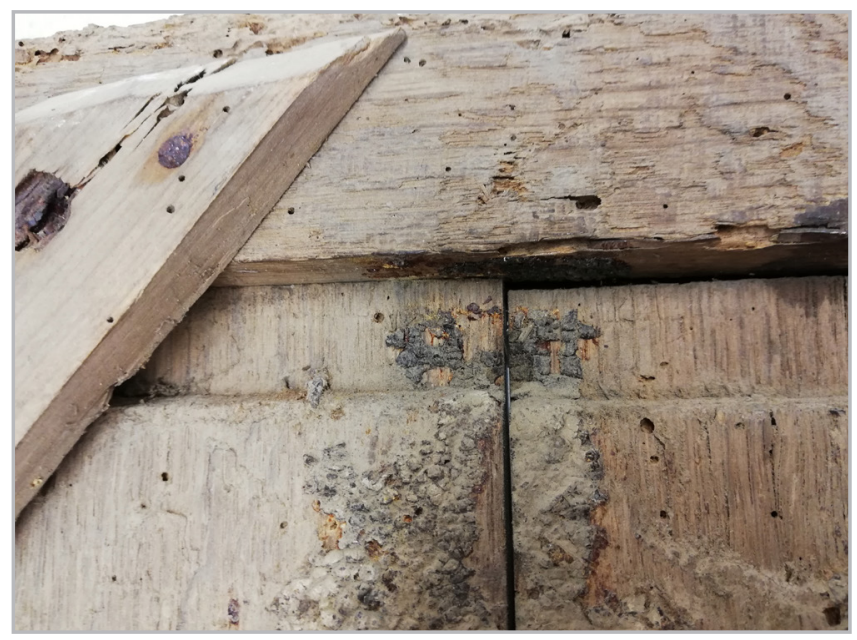

Figura 9.- Pasta na área do rebaixo que não penetrou na moldura e na face interna desta (lado superior do painel de Santa Luzia).

O reforço das juntas com tecido ou fibras era uma prática espanhola comum. Essa operação era feita imediatamente antes da aplicação da camada de preparação, nalguns casos após secagem do painel durante alguns meses, e podia incidir na frente ou no verso do painel (Bruquetas Galán 2002; Véliz 1998). As fontes documentais mencionam frequentemente a aplicação de "nervo" ou "cânhamo forte" com cola forte, isto é, cola animal, um tratamento que é designado como "enervar" ou "encañamar" (Bruquetas Galán 2002: 225-228). Segundo o tratadista Francisco Pacheco (1564-1644), no seu tempo, como a madeira usada era de boa qualidade (por exemplo, "borne", ou seja, carvalho do Báltico (Bruquetas Galán 2002: 434)), o processo estava simplificado e esse reforço, que diz fazer-se sempre mesmo quando os suportes tinham travessas, era efectuado apenas com fibras no verso do suporte, diferentemente do que se fazia antes (Pacheco 2001: 480, 506). Até há pouco considerava-se que "nervo" era sinónimo de cânhamo ou outra fibra vegetal, mas já foram identificados efectivamente nervos, isto é, tendões animais, nas juntas de algumas pinturas do espanhol Luis de Morales (c.1510-1586) (Jover et al. 2015).

Independentemente da natureza das fibras, o reforço das juntas em pinturas realizadas em Portugal só é conhecido num número muito limitado de casos: no retábulo dos Jerónimos pintado, em 1570-1572, pelo espanhol Lourenço de Salzedo (Almada, Figueira 2000), num painel executado pelo eborense Francisco João em 1592 (Melo 2012: 243) e, na forma de vestígios, num painel de 15961598 da autoria de Diogo Teixeira, o mestre de Belchior de Matos (Sousa et al. 2014). Além disso, são conhecidas referências documentais à aquisição de nervos e ao trabalho de enervar efectuado durante a reparação de uma pintura de Diogo Teixeira que ao mesmo foi contratada em 1597 (Basto 1931). A situação mais semelhante à das obras em estudo é a do painel de Francisco João, um pintor fortemente influenciado por Morales, uma vez que as fibras (que não foram identificadas) também estão misturadas com colofónia, ainda que não se limitem às juntas (Melo 2012: 243).

Em resumo, sobre a construção dos suportes pode dizerse que as tábuas, com origem no norte da Europa, foram dispostas de uma forma regular seguindo procedimentos flamengos a respeito de alguns aspectos e italianos a respeito de outros e a assemblagem, eventualmente feita de uma forma incomum sem o recurso a cola, foi realizada usando técnicas características de Espanha, especialmente de Castela.

\section{Molduras}

As molduras, de linhas simples, sem entalhes de elementos decorativos, apresentam decoração polícroma constituída por marmoreado vermelho e branco, com frisos azuis nas extremidades das partes laterais. Subjacente, através das observações com a lupa binocular e dos cortes estratigráficos, é perceptível uma policromia vermelha com friso interno dourado. Como os suportes apresentam quer margens não pintadas sem camada de preparação, quer rebarba que nalgumas zonas tem continuidade nas molduras [figura 10], as molduras foram colocadas nos suportes antes da aplicação da camada de preparação e da realização das pinturas, de acordo com as tradições medievais. Em Portugal, essa prática parecia ser comum ainda em finais do século $\mathrm{XVI}$, como é constatado através de casos de diferentes oficinas (Cordeiro 2013a: 255; Melo 2012: 290; Mendes 2004: 44; Salgado, Dias 2013), nomeadamente em obras do mestre de Belchior de Matos (Sousa et al. 2014). A ligação foi feita através do encaixe dos suportes rebaixados nas calhas das molduras [figura 9], o sistema mais frequente na pintura flamenga até ao início do século XVI (Verougstraete 2015: 66), mas que em 1600 já não era habitual em pinturas isoladas (Streeton, Wadum 2012). Em Itália e em Espanha as molduras eram geralmente pregadas, pela frente, aos suportes (Castelli 2009; Véliz 1998), ainda que em Espanha fosse também usado o sistema de encaixe em calhas (Bruquetas Galán 2013). Em Portugal, ainda que a informação publicada seja escassa, há referências a exemplos de fixação semelhante ao das pinturas em estudo (Melo 2012: 99, 247-248). Convém notar-se, no entanto, que a comparação é dificultada pelo facto de serem diferentes as molduras de pinturas isoladas e as molduras de pinturas integrantes de um retábulo, como é o caso.

De acordo com o sistema usado, as molduras e suportes formavam um só conjunto, contribuindo as molduras, portanto, para a união das tábuas dos suportes. 


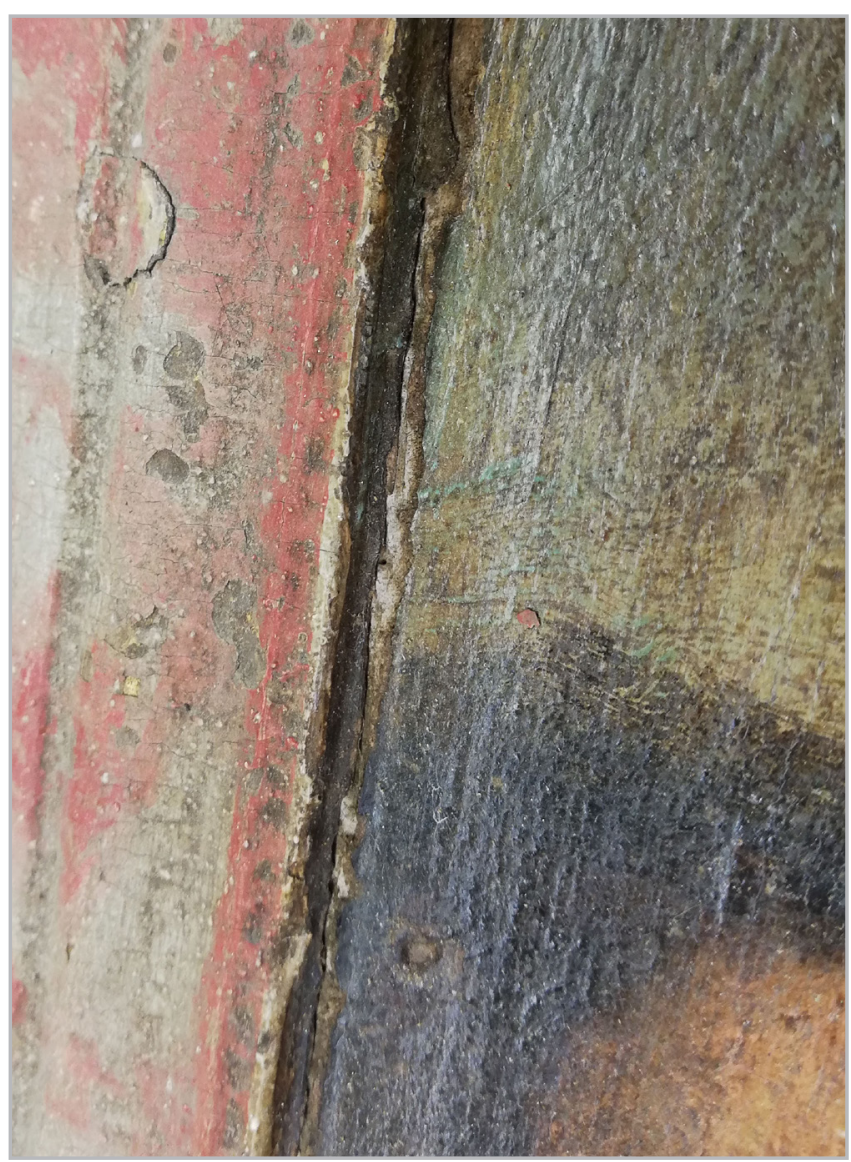

Figura 10.- Rebarba e continuidade pictórica entre o painel e a moldura, numa zona pontualmente não repintada, no painel do Martírio de São Sebastião.
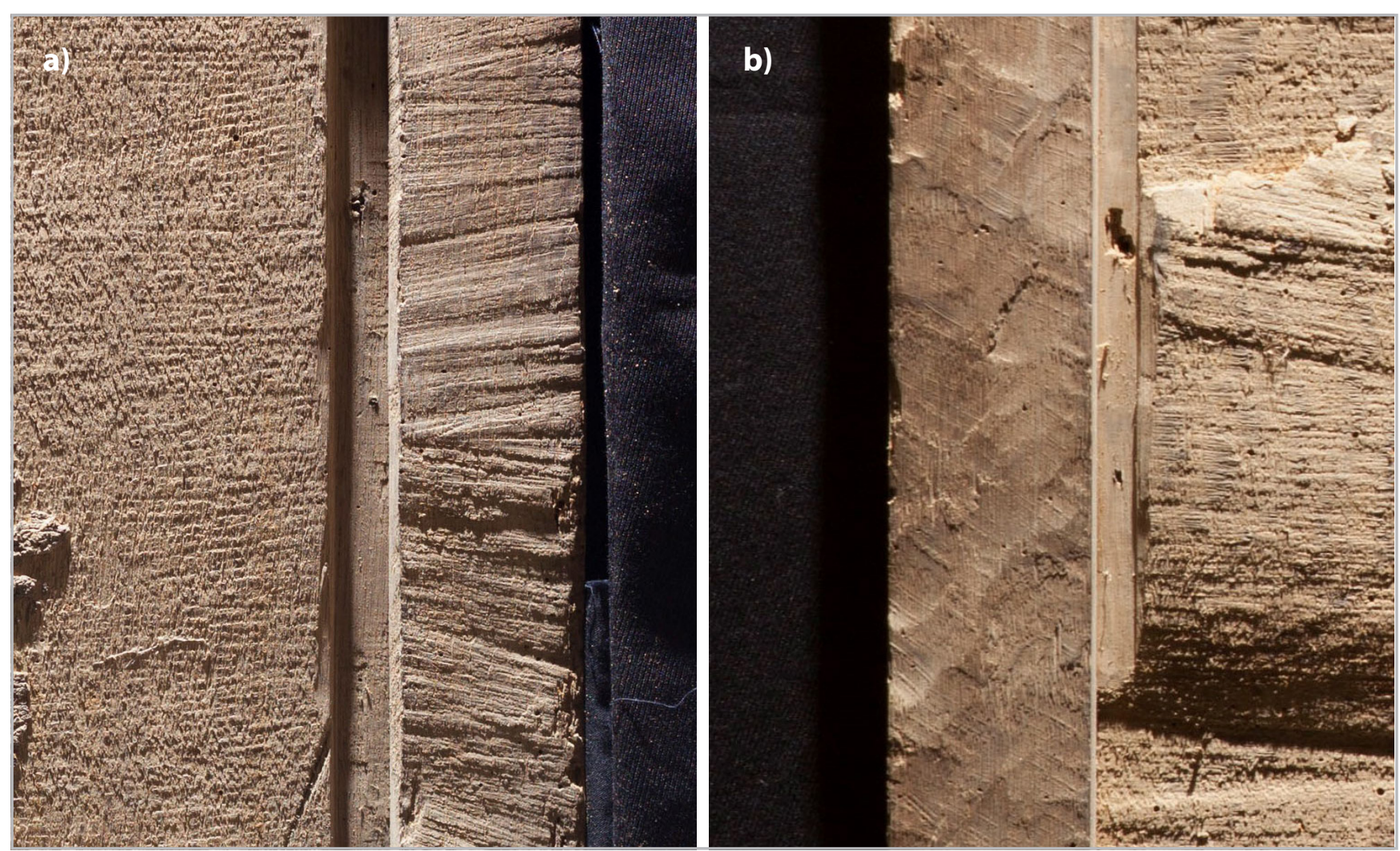

Figura 11.- Marcas no verso das molduras (fotografias de luz rasante): a) marcas de serra manual no painel de Santa Luzia; b) marcas de outra ferramenta no painel do Martírio de São Sebastião.

As molduras são de madeira que macroscopicamente parece ser de carvalho e as marcas existentes no verso das molduras sugerem o uso de serra manual, sobretudo no painel de Santa Luzia, e ferramenta cortante por percussão (possivelmente formão), sobretudo no do Martírio de São Sebastião [figura 11].

Nos cantos, os elementos verticais e horizontais unem-se mediante ligações macho-fêmea com respiga de fora a fora, travadas por cavilha circular de madeira [figura 12]. A linha de corte das ensamblagens é direita, horizontalmente no verso e mista na frente (combina uma união direita horizontal com uma união diagonal). Trata-se de um sistema que não corresponde a nenhum dos 38 tipos de assemblagem de molduras identificados por HélèneVerougstraete nas pinturas flamengas dos séculos XV e XVI (Verougstraete 2015: 50-63) e para o mesmo não se encontrou paralelo na literatura.

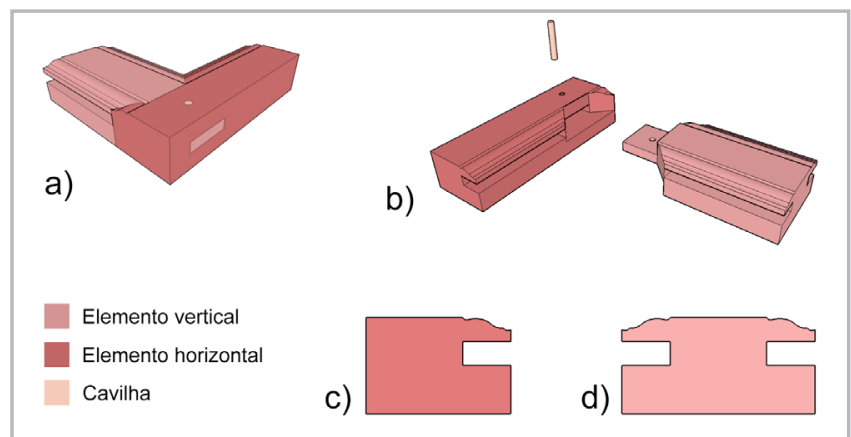

Figura 12.- Esquema do sistema de assemblagem das molduras $(a, b)$ e perfis dos elementos horizontais (c) e verticais (d). 
A orientação dos encaixes não é a melhor para a suspensão das pinturas pelo elemento superior da moldura, por colocar as cavilhas sobre tensão e facilitar o deslizamento das respigas e consequente abertura das juntas. Com efeito, esse problema era especialmente visível [figuras 1 e 2], ainda que em resultado, sobretudo, da degradação da madeira. Para o minimizar, no passado, provavelmente quando as pinturas foram colocadas nas paredes da ermida suspensas pelas peças de ferro existentes nos elementos do topo, foram colocadas tábuas nos cantos, em posição diagonal, fixas com pregos de ferro [figuras 1 e 2]. No entanto, originalmente essa fragilidade podia não ser significativa, pois o sistema de fixação à estrutura retabular era diferente.

\section{Camada de preparação}

Como já foi referido, a preparação foi aplicada depois de colocadas as molduras, de acordo com a antiga tradição de origem flamenga. Trata-se de uma camada branca, de difícil observação nos cortes estratigráficos, devido à desagregação destes, com estrutura porosa e pequenas inclusões castanhas e pretas, como se vê numa amostra, não montada em resina, de uma escorrência entre o suporte e a moldura [figura 13]. As bandas do espectro de FTIR correspondem apenas a gesso (sulfato de cálcio di-hidratado) [figura 14]. São especialmente significativas as bandas $\delta(\mathrm{S}-\mathrm{O})$ a 669 e $\mathrm{v}(\mathrm{S}-\mathrm{O})$ a $1003 \mathrm{~cm}^{-1}$, que não evidenciam qualquer deslocação ou desdobramento que ocorrem na presença de anidrite (sulfato de cálcio anidro) (Melo et al. 2014). Ainda que não seja detectável qualquer banda no espectro que possa ser atribuída ao adesivo ou aglutinante empregue, as bolhas observadas [figura 13], características de mistura de carga ou pigmento com cola animal agitada com vigor ou aplicada demasiado quente (Dunkerton 1994: 90, 108-110), permitem concluir que a preparação é de gesso com cola animal.

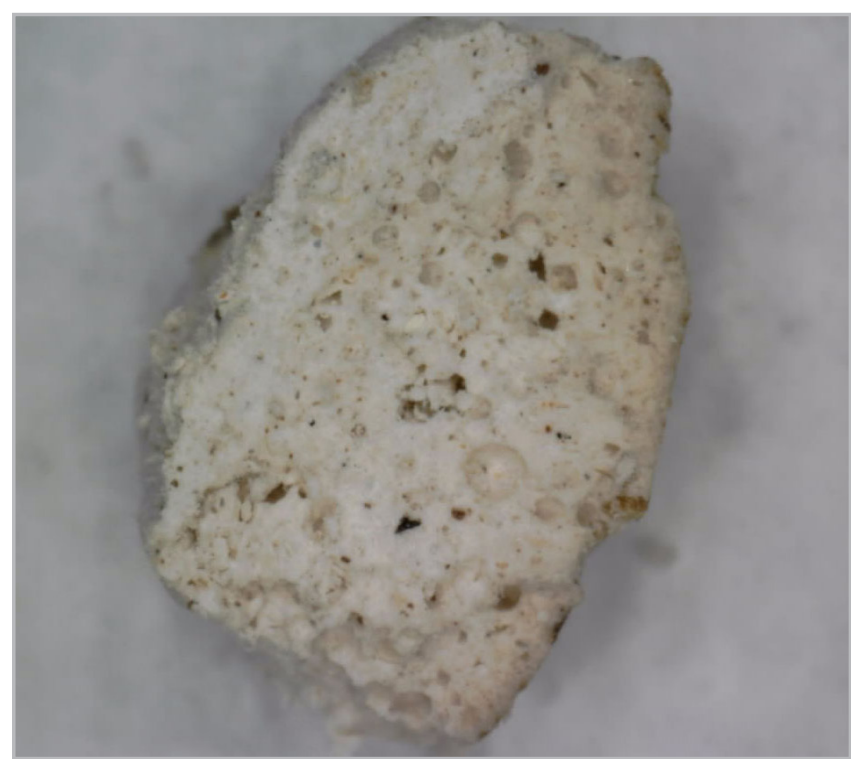

Figura 13.- Amostra da preparação observada com microscópio de mão (ampliação 50x).

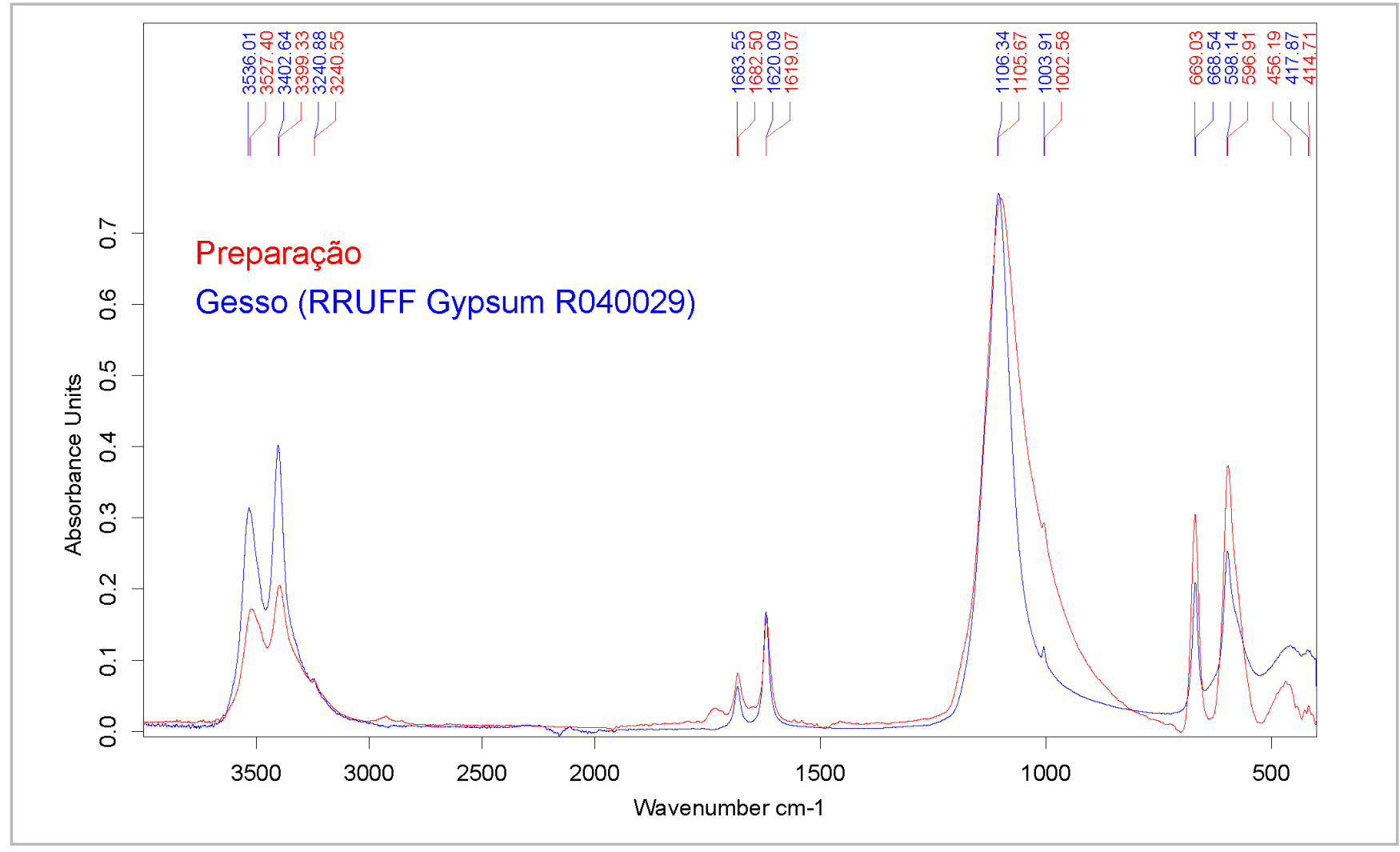

Figura 14.- Espectro de FTIR de amostra de preparação e de referência de gesso (RRUFF Project, Gypsum R040029). 
Em traços gerais, as preparações de sulfato de cálcio são características do sul da Europa, especialmente de Itália, e as de carbonato de cálcio do norte da Europa, mas a situação é mais complexa. Por um lado, no sul da Europa, nomeadamente em Portugal e em Espanha, também eram usadas preparações de carbonato de cálcio, ainda que menos frequentemente (Antunes et al. 2013; Calvo et al. 2013). Por outro lado, o sulfato de cálcio era usado quer na forma anidra (anidrite), quer na forma hidratada (gesso), separadamente ou misturadas, num só estrato ou numa sequência de dois estratos. Apenas gesso, como sucede nas pinturas em estudo, era pouco comum quer em Portugal (Antunes et al. 2013; Antunes 2014; Oliveira et al. 2013), quer em Espanha (Calvo et al. 2013), quer em Itália (Gettens, Mrose 1954).

Esse uso apenas de gesso é caso único no conjunto de pinturas já estudadas de alguma forma relacionadas com Belchior de Matos. Com efeito, nas pinturas de Diogo Teixeira da Misericórdia do Porto, onde Belchior de Matos colaborou como aprendiz, sendo responsável por engessar e aparelhar as tábuas, a preparação é, essencialmente, de anidrite (Antunes 2014: 687-688); na Lamentação, da Igreja de Miragaia (Porto), atribuída a Belchior de Matos, a preparação é igualmente de anidrite (Antunes 2014: 305); e no Pentecostes pintado por Belchior de Matos, c. 1600, para igreja da Lourinhã, a preparação é de uma mistura de anidrite e, em menor concentração, gesso (Antunes 2014: 688-689).

Portanto, a composição da camada de preparação das pinturas em estudo é pouco comum qualquer que seja o enquadramento considerado.

\section{Discussão e conclusão}

Se a datação por dendrocronologia das duas pinturas de Belchior de Matos está de acordo com o esperado, as características dos suportes são muito diferentes do que seria previsível encontrar em duas obras mal pagas realizadas numa pequena oficina de província, no início do século XVII, por um pintor sem grande domínio das técnicas artísticas:

- a madeira dos suportes é de excelente qualidade, seja devido à espécie e origem, seja devido ao corte das tábuas, originando suportes que não tiveram deformação significativa

- a disposição das tábuas segue um padrão regular, num aspecto de acordo com práticas de origem flamenga, noutro adoptando hábitos italianos

- a junção das tábuas foi feita de modo pouco comum, mas com reforços no verso efectuados tal como era habitual em Espanha, especialmente em Castela, e, no que diz respeito à pasta aplicada nas juntas, de acordo com procedimentos que, segundo o tratadista
Francisco Pacheco, eram novos no seu tempo

- em contrapartida, a colocação da moldura antes da camada de preparação e a ligação da moldura ao suporte seguiu uma antiga tradição flamenga, frequente em Portugal

- a assemblagem das molduras foi efectuada com um tipo de encaixes que não encontrámos na literatura

- finalmente, a natureza da preparação, ainda que no geral de acordo com a tradição mediterrânica, corresponde a uma forma de sulfato de cálcio (forma di-hidratada) que, isoladamente como aconteceu nestas pinturas, era pouco usada

Portanto, além da contradição entre a qualidade da madeira e a qualidade da pintura, os resultados obtidos mostram uma prática ecléctica, onde se mistura a originalidade com as diferentes influências geográficas e os procedimentos antigos com os mais modernos. Se os procedimentos antigos podem ser interpretados como arcaísmo que facilmente se compreende em oficinas de província, o mesmo não sucede com os procedimentos mais modernos. Por outro lado, trata-se de pinturas de influências formais italianas, mas realizadas com procedimentos técnicos que têm sobretudo outras origens. Ou seja, do ponto de vista técnico, esta oficina parecia não estar tão isolada do mundo como as limitadas ambições artísticas e os escassos recursos económicos poderiam sugerir.

Seriam este eclectismo e estas contradições reflexo da divisão de tarefas envolvidas numa empreitada? Em parte podem ser, pois, de acordo com a legislação da época, como o regimento dos marceneiros de Lisboa, de 1572, a construção dos painéis usados como suporte de pintura era da exclusiva competência dos assembladores (Correia 1926: 109-110). Aliás, no anterior regimento dos assembladores, de 1549, era expressamente referido que "nenhum pintor de qualquer arte que seja não tomará nenhuma obra de madeira de qualquer sorte e maneira que seja" (Langhans 1943: 467). Estas são referências significativamente anteriores às pinturas em estudo, mas durante muito tempo, e até consideravelmente mais tarde, se mantiveram anacronicamente em vigor em Portugal, nomeadamente nas pequenas e obscuras oficinas regionais, procedimentos e práticas de origem medieval (Serrão 1983; Serrão 2001). Além disso, há inclusivamente uma referência documental ao trabalho realizado por um marceneiro para uma obra pintada por Belchior de Matos, em 1626, para a Misericórdia de Óbidos (Serrão 1981: 26-27).

Relativamente à preparação dos painéis, considerando as já mencionadas numerosas referências documentais aos trabalhos de engessar adjudicados a Belchior de Matos ao longo da sua carreira baseada nas Caldas da Rainha, é muito provável que a aplicação da camada de 
gesso aos painéis tenha sido efectuada pelo pintor ou, à semelhança do que ocorria mesmo em pequenas oficinas como a sua (Serrão 2001) e tinha acontecido com ele quando esteve ao serviço do seu mestre Diogo Teixeira, por qualquer eventual ajudante ou aprendiz sob a sua responsabilidade.

De qualquer forma, não obstante o quase certo envolvimento de mestre marceneiro na construção dos suportes onde Belchior de Matos executou as pinturas (ainda que possivelmente construídos de acordo com as suas indicações), as múltiplas e diversificadas influências detectadas nos suportes estudados e as suas características mostram que as obras saídas das oficinas regionais de pintura, por um lado, podiam ter materiais de qualidade muito superior ao seu merecimento artístico e, por outro lado, podiam surgir num imprevisto ambiente de diversificados conhecimentos técnicos que, além de soluções originais, envolvia práticas provenientes de muitas e desvairadas partes.

Uma questão que se pode colocar é se os procedimentos técnicos observados nas duas pinturas, apresentados neste artigo, são exclusivo desta oficina ou se as mesmas práticas eram comuns noutras oficinas, em particular nas de implantação regional. Dito de outra forma, será que as diversas influências aqui encontradas estavam assimiladas nas oficinas portuguesas e, consequentemente, correspondiam simplesmente a uma prática nacional? Parece-nos que a escassa literatura que aborda com detalhe as características técnicas dos suportes de madeira usados na época em Portugal não permite uma resposta neste momento, sendo necessários mais estudos de casos.

Independentemente da situação a este respeito, noutra perspectiva, este artigo mostra que os estudos realizados no contexto de uma intervenção de conservação e restauro podem proporcionar informação importante para a abordagem de problemas da História da Arte que dificilmente poderia ser obtida de outra forma.

\section{Agradecimentos}

Agradece-se a Gonçalo Figueiredo (IPT) as fotografias gerais e a Vítor Gaspar (IPT) as análises por microscopia óptica e FTIR. AJC agradece a Helena Melo (Laboratório HERCULES) as numerosas informações sobre aspectos importantes relacionados com a produção dos painéis de madeira usados em pintura.

\section{Referências}

ALBA GONZÁLEZ-FANJUL, T. (2015). La construcción de los soportes pictóricos de madera en Castilla: siglos XV y XVI. Tese de doutoramento. Universidad Complutense de Madrid. http:// eprints.ucm.es/33197/.
ALMADA, C. O., FIGUEIRA, L. T. (2000). “Conservação e restauro 1998-1999". In: História e Restauro da Pintura do Retábulo-mor do Mosteiro dos Jerónimos. Lisboa: IPPAR: 81-290.

ANTUNES, V., SERRÃO, V., OLIVEIRA, M. J., DIAS, L., CANDEIAS, A., MIRÃO, J., COROADO, J., CARVALHO, M. L., SERUYA, A. I. (2013). "Técnicas e materiais de preparação na pintura portuguesa dos séculos XV e XVI". In: As Preparações na Pintura Portuguesa. Séculos XV e XVI, Serrão, V., Antunes, V. \& Seruya, A. I. (eds.). Lisboa: Faculdade de Letras da Universidade de Lisboa: 55-74.

ANTUNES, V. H. (2014). Técnicas e Materiais de Preparação na Pintura Portuguesa dos Séculos XV e XVI. Tese de doutoramento. Faculdade de Letras da Universidade de Lisboa.

AZÉMARD, C., VIEILLESCAZES, C., MÉNAGER, M. (2014). “Effect of photodegradation on the identification of natural varnishes by FT-IR spectroscopy", Microchemical Journal, 112: 137-149. https://doi.org/10.1016/j.microc.2013.09.020.

BASTO, A. M. (1931). O Pintor Quinhentista Diogo Teixeira. Gaia: Edições Pátria.

BRUQUETAS GALÁN, R. (2002). Técnicas y Materiales de la Pintura Española en los Siglos de Oro. Madrid: Fundación de Apoyo a la Historia del Arte Hispánico.

BRUQUETAS GALÁN, R. (2013). “Aparejos e imprimaduras. La preparación de la pintura según las fuentes históricas españolas". In: As Preparações na Pintura Portuguesa. Séculos XVe XVI, Serrão, V., Antunes, V. \& Seruya, A. I. (eds.). Lisboa: Faculdade de Letras da Universidade de Lisboa: 27-37.

CALVO, A., SANTOS, S., ANDRÉS, M. S., SOUSA, M. J., CRUZ, A. J. (2013). “Del Mediterráneo al Atlántico: algunas consideraciones sobre las preparaciones de la pintura sobre tabla en la península ibérica". In: As Preparações na Pintura Portuguesa. Séculos XV e XVI, Serrão, V., Antunes, V. \& Seruya, A. I. (eds.). Lisboa: Faculdade de Letras da Universidade de Lisboa: 95-106. http://www.ciarte. pt/artigos/201303.html.

CAMPBELL, L., FOISTER, S. (1997). "Methods and materials of Northern European painting in the National Gallery, 1400-1550", National Gallery Technical Bulletin, 18: 6-55.

CASTELLI, C. (2009). "The construction of wooden supports of late medieval altarpieces". In: Sassetta. The Borgo San Sepolcro Altarpiece, Israëls, M. (ed.). Leiden: Primavera Press: 319-336.

CORDEIRO, F. R. (2013a). Thomas Luis, Pintor Maneirista do Sacro e do Profano: Arte, Conservação e Restauro. Casos de Évora, Aldeia Galega, Elvas, Idanha-a-nova e Vila Viçosa - Séculos XVI a XVII. Tese de doutoramento. Faculdade de Letras da Universidade de Lisboa. http://hdl.handle.net/10451/11426.

CORDEIRO, F. R. (2013b). "Altarpieces in Portugal: joinery techniques within the context of fifteenth- and sixteenthcentury European workshop practice". In: The Renaissance Workshop. The Materials and Techniques of Renaissance Art, 
Saunders, D., Spring, M., Meek, A. (eds.). London: Archetype Publications: 49-59.

CORREIA, V. (1926). Livro dos Regimentos dos Officiaes Mecanicos da Mui Nobre e Sempre Leal Cidade de Lixboa (1572). Coimbra: Imprensa da Universidade.

DERRICK, M. R., STULIK, D., LANDRY, J. M. (1999). Infrared Spectroscopy in Conservation Science. Los Angeles: The Getty Conservation Institute. http://hdl.handle.net/10020/gci pubs/ infrared spectroscopy.

DUBOIS, H., FRAITURE, P. (2011). "Between creativity and economy: remarks on the quality of Rubens' panel supports. A study of paintings in the Royal Museums of Fine Arts of Belgium". In: Studying Old Master Paintings. Technology and Practice, Spring, M. (ed.). London: Archetype Publications: 136-142.

DUNKERTON, J. (1994). "Michelangelo as a painter on panel". In: Making \& Meaning. The Young Michelangelo, Hirst, M. \& Dunkerton, J. (eds.). London: National Gallery Publications: 83-133.

DUNKERTON, J., FOISTER, S., PENNY, N. (1999). Dürer to Veronese. Sixteen-Century Painting in the National Gallery. London: National Gallery Company.

ECKSTEIN, D. \& BAUCH, J. (1969). “Beitrag zur rationalisierung eines dendrochronologischen verfahrens und zur analyse seiner aussagesicherheit", Forstwissenschaftliches Centralblatt, 88(1): 230-250. https://doi.org/10.1007/BF02741777.

ESTEVES, L. (2003). "A dendrocronologia aplicada às obras de arte". Documento dactilografado. Lisboa: Instituto Português de Conservação e Restauro.

FRAITURE, P. (2012). "Dendro-archaeological Examination of Paintings by Pieter Brueghel the Younger". In: The Brueg(h) el Phenomenon. Paintings by Pieter Bruegel the Elder and Pieter Brueghel the Younger with a Special Focus on Technique and Copying Practice, Currie, C. \& Allart, D. (eds.). Brussels: Royal Institute for Cultural Heritage: 1002-1016.

GETTENS, R. J., MROSE, M. E. (1954). "Calcium sulfate minerals in the grounds of Italian paintings", Studies in conservation, 1(4): 174-189. https://doi.org/10.1179/sic.1954.026.

HILLAM, J., TYERS, I. (1995). "Reliability and repeatability in dendrochronological analysis: tests using the Fletcher archive of panel-painting data", Archaeometry, 37(2): 395-405. https:// doi.org/10.1111/j.1475-4754.1995.tb00752.x.

HODGE, S., SPRING, M., MARCHANT, R. (1998). "The construction and painting of a large Castilian retable: a study of techniques and workshop practices". In: Painting Techniques. History, materials and studio practice. Contributions to the Dublin Congress. 7-11 September 1998, Roy, A. \& Smith, P. (eds.). London: The International Institute for Conservation of Historic and Artistic Works: 70-76. https://doi.org/10.1179/sic.1998.43. Supplement-1.70.
HOLLSTEIN, E. (1980). Mitteleuropäische Eichenchronologie. Mainz am Rhein: Verlag Philipp von Zabern.

ILVESSALO-PFÄFFLI, M. S. (1995). Fiber Atlas Identification of Papermaking Fibers. Berlin: Springer.

JOVER, M., ALBA, L., GAYO, M. D. \& GARCÍA-MÁIQUEZ, J. (2015). "El taller del pintor: procedimientos artísticos en el obrador de Luis de Morales". In: El Divino Morales, Gómez, L. R. (ed.). Madrid: Museo Nacional del Prado: 213-225.

KLEIN, P. (2010). “Dendrochronological analyses of Netherlandish panel paintings". In: La Pintura Europea Sobre Tabla. Siglos XV, XVIy XVII. Madrid: Ministerio de Cultura: 94-99. https://dialnet.unirioja. es/servlet/articulo?codigo $=4086462$.

KLEIN, P. (2012). "Wood identification and dendrochronology". In: The Conservation of Easel Paintings, Stoner, J. H. \& Rushfield, R. (eds.). Abingdon: Routledge: 51-65.

LANGHANS, F. P. (1943). As Corporações dos Ofícios Mecânicos. Subsídios para a sua História. Lisboa: Imprensa Nacional.

LAUW, A., ESTEVES, L., TELES, M., LEAL, S., PEREIRA, H. (2013). "Pinturas do século XV eXVI: uma abordagem dendrocronológica". In: As Preparações na Pintura Portuguesa. Séculos XV e XVI, Serrão, V., Antunes, V. \& Seruya, A. I. (eds.). Lisboa: Faculdade de Letras da Universidade de Lisboa: 279-287.

MARIJNISSEN, R. H. (1985). Paintings. Genuine, Fraud, Fake. Modern Methods of Examining Paintings. Brussels: Elsevier.

MELO, H. F. P. P. (2012). O Pintor Francisco João (Act. 1563-1595). Materiais e Técnicas na Pintura de Cavalete em Évora na Segunda Metade do Século XVI. Tese de doutoramento. Universidade Católica Portuguesa, Escola das Artes. http://repositorio.ucp.pt/ handle/10400.14/14977.

MELO, H. P., CRUZ, A. J., CANDEIAS, A., MIRÃO, J., CARDOSO, A. M., OLIVEIRA, M. J., VALADAS, S. (2014). "Problems of analysis by FTIR of calcium sulphate-based preparatory layers: the case of a group of 16th-century Portuguese paintings", Archaeometry, 56(3): 513526. https://doi.org/10.1111/arcm.12026.

MELO, H. P. (2019). Comunicação pessoal, 2019-06-20.

MENDES, J. (2004). "Intervenção de conservação e restauro". In: Retábulo de Ferreira do Alentejo. Lisboa: Instituto Português de Conservação e Restauro: 43-63.

MONTEIRO, P., CRUZ, A. J. (2010). "Breve Tratado de lluminação composto por um religioso da Ordem de Cristo". In: The Materials of the Image. As Matérias da Imagem, Afonso, L. U. (ed.). Lisboa: Cátedra de Estudos Sefarditas «Alberto Benveniste» da Universidade de Lisboa: 237-286. http://www.ciarte.pt/ artigos/201011.html.

OLIVEIRA, M. J., ANTUNES, V., SERRÃO, V., CANDEIAS, A., SERUYA, A. I., MIRÃO, J., COROADO, J. (2013). “Caracterização material da 
camada preparatória de pintura portuguesa por u-XRD e SEMEDS". In: As Preparações na Pintura Portuguesa. Séculos XV e XVI, Serrão, V., Antunes, V. \& Seruya, A. I. (eds.). Lisboa: Faculdade de Letras da Universidade de Lisboa: 39-44.

PACHECO, F. (2001). El Arte de la Pintura. Madrid: Ediciones Cátedra.

PRATI, S., SCIUTTO, G., MAZZEO, R., TORRI, C., FABBRI, D. (2011). "Application of ATR-far-infrared spectroscopy to the analysis of natural resins", Analytical and Bioanalytical Chemistry, 399(9): 3081-3091. https:// doi.org/10.1007/s00216-010-4388-y

SALGADO, A., DIAS, J. (2013). “Análise tecnológica dos suportes lenhosos. Análise dos processos de restauro do retábulo da igreja da Misericórdia de Almada". In: As Preparações na Pintura Portuguesa. Séculos XV e XVI, Serrão, V., Antunes, V. \& Seruya, A. I. (eds.). Lisboa: Faculdade de Letras da Universidade de Lisboa: 273-277.

SERRÃO, V. (1981). Belchior de Matos, 1595 - 1628. Pintor das Caldas da Rainha. Caldas da Rainha: Museu de José Malhoa.

SERRÃO, V. (1983). O Maneirismo e o Estatuto Social dos Pintores Portugueses. Lisboa: Imprensa Nacional - Casa da Moeda.

SERRÃO, V. (1989). “Belchior de Matos, um pintor de província”. In: Estudos de Pintura Maneirista e Barroca. Lisboa: Caminho: 169-177.

SERRÃO, V. (2001). “Um contrato de ensino de pintura em Castelo Branco em 1732". In: A Cripto-história da Arte. Análise de Obras de Arte Inexistentes. Lisboa: Livros Horizonte: 201-214.

SILVA, J. H. P. (1996). Estudos sobre o Maneirismo. Lisboa: Editorial Estampa.

SOUSA, M. J., CRUZ, A. J. (2012). “Materiais e técnica do painel representando a Visitação executado para o retábulo da capela de Santa Isabel (Porto), pelo pintor maneirista Diogo Teixeira", ECR - Estudos de Conservação e Restauro: 4: 210-230. https://doi. org/10.34618/ecr.4.3093.

SOUSA, M. J., CRUZ, A. J., CALVO, A. (2014). "Estudo técnico e material do suporte das pinturas de Diogo Teixeira realizadas para o Mosteiro de Arouca", ECR - Estudos de Conservação e Restauro, 6: 38-59. https://doi.org/10.7559/ecr.6.7523.

STREETON, N., WADUM, A. J. (2012). “Northern European panel paintings". In: The Conservation of Easel Paintings, Stoner, J. H. \& Rushfield, R. (eds.). Abingdon: Routledge: 86-97.

UZIELLI, L. (1998). "Historical overview of panel-making techniques in Central Italy". In: The Structural Conservation of Panel Paintings, Dardes, K. \& Rothe, A. (eds.). Los Angeles: The Getty Conservation Institute: 110-135. http://www.getty.edu/ conservation/publications/pdf publications/panelpaintings. html.

VÉLIZ, Z. (1998). "Wooden panels and their preparation for painting from the middle ages to the seventeenth century in Spain". In: The Structural Conservation of Panel Paintings, Dardes, K. \& Rothe, A. (eds.). Los Angeles: The Getty Conservation Institute: 136-148. http://www.getty.edu/conservation/publications/pdf publications/panelpaintings.html.

VEROUGSTRAETE, H. (2015). Frames and Supports in 15th and 16th-century Southern Netherlandish Painting. Brussels: Royal Institute for Cultural Heritage. http://www.kikirpa.be/uploads/ files/frames.pdf.

WADUM, J. (1998). "Historical overview of panel-making techniques in the Northern countries". In: The Structural Conservation of Panel Paintings, Dardes, K. \& Rothe, A. (eds.). Los Angeles: The Getty Conservation Institute: 149-177. http:// www.getty.edu/conservation/publications/pdf publications/ panelpaintings.html

\section{Autor/es}

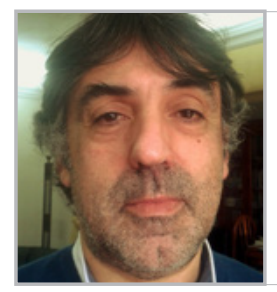

\section{António João Cruz}

ajcruz@ipt.pt

Techn\&Art, Centro de Tecnologia, Restauro eValorização das Artes; Instituto Politécnico de Tomar; Laboratório HERCULES, Universidade de Évora. Portuqal

Possui licenciatura em Química (1986) e doutoramento em Química Analítica (1993) pela Faculdade de Ciências da Universidade de Lisboa. Colaborou com o então Instituto José de Figueiredo (Lisboa) entre 1992 e 1997. Desde 1995, tem leccionado em diversos cursos de licenciatura, mestrado e doutoramento de Conservação e Restauro e de outras áreas relacionadas com o Património Cultural. Actualmente é Professor Adjunto no Instituto Politécnico de Tomar e director do respectivo Mestrado em Conservação e Restauro. Interessase pelo estudo laboratorial de obras de arte, a história da Conservação e Restauro e os problemas da relação entre a Conservação e Restauro e as outras áreas do conhecimento. Entre 2005 e 2019 foi director da revista "Conservar Património" (indexada na Scopus e na Web of Science).

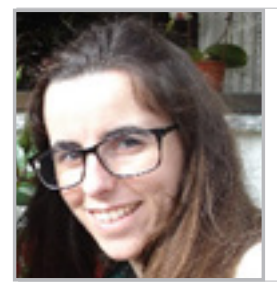

\section{Elisabete Ferreira}

lis.m.ferreira@gmail.com

Instituto Politécnico de Tomar, Estrada da Serra. Portugal

Possui licenciatura em Conservação e Restauro pelo Instituto Politécnico de Tomar (2017). Concluiu o mestrado em Conservação e Restauro, especialidade em pintura de cavalete, também no Instituto Politécnico de Tomar (2019). O presente artigo tem origem no estágio final que realizou no âmbito do mestrado. 


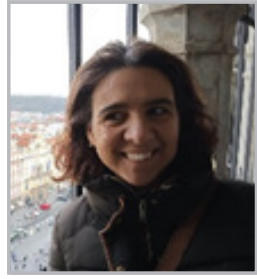

\author{
Alexandra Lauw \\ alexandralauw@isa.ulisboa.pt \\ Centro de Estudos Florestais, Instituto \\ Superior de Agronomia, Universidade de \\ Lisboa. Portugal
}

Licenciada em Engenharia Florestal pelo Instituto Superior de Agronomia (ISA) em 1996, inicia a sua actividade como bolseira de investigaçãono Centro deEstudosFlorestais (CEF). Em 2003, trabalha no sector privado, regressando ao ISA, em 2010, para obtenção do grau de Mestre em Engenharia Florestal e dos Recursos Naturais, com a tese final na área da dendrocronologia. Desde 2011 a 2014, dá continuidade à investigação na área da dendroclimatologia e da dendroarqueologia, estabelecendo, para tal, parcerias com centros de investigação de universidades portuguesas, museus e entidades privadas. A formação complementar e contínua realizou-se pelos estágios na Universidade de Hamburgo (Alemanha, 1998), WSL Birmensdorf, Swiss Federal Research Institute (Suíça, 2010), Institut Royal du Patrimoine Artistique (Bélgica, 2012) e Universidade de Ljubljana (Eslovénia, 2016). Em 2014 inicia o seu Doutoramento com uma abordagem dendrocronológica e de anatomia vegetal aplicada à pintura e instrumentos musicais.
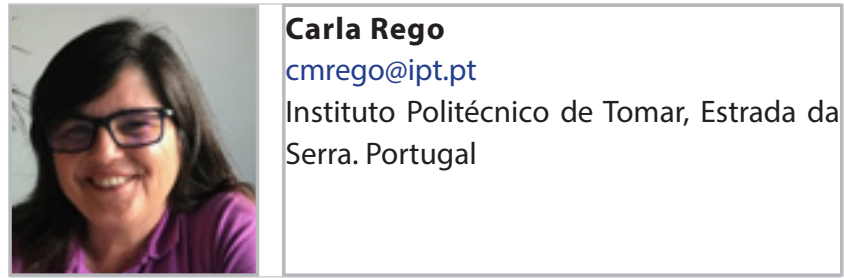

É Professora Adjunta no Instituto Politécnico de Tomar, na Unidade Departamental de Arqueologia, Conservação e Restauro e Património. É investigadora no Techn\&Art, Centro de Tecnologia, Restauro e Valorização das Artes, Instituto Politécnico de Tomar. Realizou com aproveitamento a parte curricular e Prova de Suficiência Investigadora do Doutoramento em Bines Culturales, da Universidade do País Basco. É Mestre em Museologia e Património Cultural, da Universidade de Coimbra. Desde 1997 que exerce a actividade de conservadorarestauradora de Pintura e Escultura, no Laboratório de Conservação e Restauro - IPT.
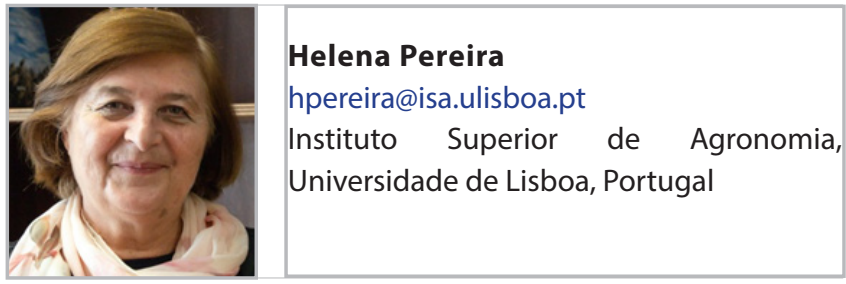

Professora catedrática do Instituto Superior de Agronomia, Universidade de Lisboa. Engenheira química (Instituto Superior Técnico), doutorada (Dr. rer. nat.) pela Faculdade de Biologia, Universidade de Hamburgo, com agregação no Instituto Superior de Agronomia, Universidade de Lisboa. Desempenhou diversos cargos de gestão académica e científica em Universidades,
Institutos Politécnicos e Instituições de Investigação Científica. Áreas de investigação: florestas e produtos florestais, biomassa, bioenergia e biorefinarias. Orientou mais de 40 teses de doutoramento. Possui cerca de 400 publicações científicas internacionais, em livros, capítulos de livros e revistas científicas de editoras reconhecidas.

Artículo enviado el 24/11/2019 Artículo aceptado el 09/04/2020

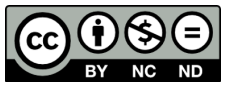

https://doi.org/10.37558/gec.v17i1.700 